JOSÉ ROBERTO DE OLIVEIRA BAUER

\title{
PROPRIEDADES MECÂNICAS DO TITÂNIO \\ COMERCIALMENTE PURO E DA LIGA Ti-6AI-4V FUNDIDOS \\ EM DIFERENTES AMBIENTES
}


José Roberto de Oliveira Bauer

Propriedades mecânicas do titânio comercialmente puro e da liga Ti-6Al-4V fundidos em diferentes ambientes

Tese apresentada à Faculdade de Odontologia da Universidade de São Paulo, para obter o título de Doutor pelo Programa de Pós-Graduação em Odontologia.

Área de Concentração: Materiais Dentários

Orientador: Prof. Dr. Leonardo Eloy Rodrigues Filho 

Bauer JRO. Propriedades mecânicas do titânio comercialmente puro e da liga Ti-6Al$4 \mathrm{~V}$ fundidos em diferentes ambientes [Tese de Doutorado]. São Paulo: Faculdade de Odontologia da USP; 2007.

São Paulo, ____

\section{Banca Examinadora}

1) $\operatorname{Prof}(a) . \operatorname{Dr}(a)$.

Titulação:

Julgamento:

Assinatura:

2) $\operatorname{Prof}(a) . \operatorname{Dr}(a)$.

Titulação:

Julgamento:

Assinatura:

3) $\operatorname{Prof}(a) . \operatorname{Dr}(a)$.

Titulação:

Julgamento:

Assinatura:

4) $\operatorname{Prof}(a) . \operatorname{Dr}(a)$.

Titulação:

Julgamento:

Assinatura:

5) $\operatorname{Prof}(a) . \operatorname{Dr}(a)$.

Titulação:

Julgamento:

Assinatura: 


\section{DEDICATÓRIA}

Dedico esta tese

Ao meu Deus, por ter dado energia às pessoas que estão à minha volta, e por tornar possível este momento.

À minha doce e adorável mamãe Mariza, pelo carinho e amor inesgotável dedicado a toda família e pela serenidade e força de vontade em um momento quando não havia mais esperança.

Ao meu amado pai Manoel, por ter escolhido o melhor caminho para que eu chegasse a este momento. Pai, você é um herói, por isso eu te amo tanto.

Aos meus irmãos, Maristela, Guilherme e Mauricio, pela companhia e carinho.

Aos meus queridos sobrinhos Bruna, Juninho, Júlia, Rodrigo, Gabriela e o caçula Gabriel.

À minha amada $\underline{\text { Ceci, }}$ pois sua presença torna os obstáculos da vida extremamente insignificantes e faz dela uma maravilhosa conquista. Obrigado por me fazer uma pessoa melhor. Amo-te mais do que tudo.

À minha querida mãenzona Rosa Helena, pela oportunidade, amor e confiança no meu potencial. À competente Solimar, que foi um anjo, a minha eterna gratidão..

Aos maravilhosos amigos e irmãos que a vida me deu a oportunidade de escolher,

Alessandro e Alessandra, com muito carinho, dedicação e amor. Vocês são os grandes responsáveis por tudo isso. 
"A coisa mais injusta sobre a vida é a maneira como ela termina. Eu acho que o verdadeiro ciclo da vida está todo de trás pra frente. Nós deveríamos morrer primeiro, nos livrar logo disso. Daí viver num asilo, até ser chutado pra fora de lá por estar muito novo. Ganhar um relógio de ouro e ir trabalhar. Então você trabalha 40 anos até ficar novo o bastante pra poder aproveitar sua aposentadoria. Aí você curte tudo, bebe bastante álcool, faz festas e se prepara para a faculdade. Você vai para colégio, tem várias namoradas, vira criança, não tem nenhuma responsabilidade, se torna um bebezinho de colo, volta pro útero da mãe, passa seus últimos nove meses de vida flutuando. E termina tudo com um ótimo orgasmo! Não seria perfeito?” 


\section{AGRADECIMENTOS}

Ao meu orientador Prof. Dr. Leonardo Eloy Rodrigues Filho, por ter me conduzido com competência e zelo nesses anos de aprendizado. Além de grande amigo, meu "melhor" companheiro zaga nas peladas no "areião" do CEPEUSP.

Ao inigualável Prof. Dr. Antonio Muench, pelo seu carinho e amizade. Obrigado pela presença marcante na minha formação profissional e pelo exemplo científico que me transmitiu.

Ao querido e saudoso Prof. Dr. Joel Bianchi, por dedicar horas de sua vida me explicando coisas simples, mas que eu não entendia de jeito nenhum.

Ao grande amigo e irmão Marcelo Mendes, pela ajuda na tese e pelas caronas doidas na motoca e as normais. Agradeço principalmente por você ser meu amigo.

À minha queridíssima e divertida Rosa Cristina, por me receber todos os dias com esse lindo sorriso e por estar sempre disposta a me ajudar.

Aos amigos de república Marcelo Lammers e José Antonio, por terem me ajudado muito no momento mais difícil de minha vida. Por terem recebido a minha família como se fosse a de vocês. Ao sempre querido amigo José Luis, valeu pela força e amizade. A todos vocês, obrigado pelos momentos de alegria, principalmente aqueles do Pé sujo.

Ao mais que amigo Marcos Schroeder, por estar sempre presente na minha vida e por fazer parte deste sonho.

À minha linda Marcela Carrilho, pela força e carinho mesmo de muito longe.

Aos extraordinários Antônio Carlos Lascala, Silvio Peixoto e, o agora carioca, Paulo Santos, a quem devo um grande muito obrigado pela ajuda em todos os trabalhos e pela companhia agradável no dia-dia. À Mirtes Saduto, pela torcida de sempre.

Ao meu querido companheiro Prof. Dr. Alberto Sansiviero, que até hoje, depois de tanto tempo de convívio, eu ainda não descobri se é um irmão ou um segundo pai. Ao 
carinhoso Carlos Aberto Tavares Jr., por sua amizade fantástica e pelos momentos hilários que passamos juntos.

Em nome do Chefe do Departamento de Biomateriais e Bioquímica Oral, Prof. Dr. Roberto Ruggiero Braga, agradeço a todos os professores, em especial o professor $\underline{\mathrm{Dr}}$. Igor Medeiros, pela ajuda na elaboração dos gráficos.

Aos colegas de pós Cláudio Sato, Glauco Botelho, Carmem Pfeifer, Carla Gonçalves, Edméa Ludovici, Herbert Ghersel, Laiza Tatiana, Walter Siqueira, Sandra Kiss, Andréa Urbano, Fábio Zovico, José Ferreira, Ana Maria, Ivone Lima, Soraya de Fátima, Adriana Vasconcelos, Fernanda Calheiros, Fernanda Sadek, Flávia Gonçalves, Flávia Pires, Janaína Lima, Maurício Gomes, Nívea Fróes, Breno, Andréa, Silvia Kenshima, Tathy Xavier e Jonas Matos.

Ao meu querido gremista e companheiro de viagem Vinícius Rosa, minha fonte de inspiração no mais famoso esporte bretão.

Aos meus queridos amigos Mário Sady, Darcy Nóbile, Milton Masuda, Ricardo Sigmori, Rodrigo Del Mônaco, Jansen Ozaki, Waldyr Romão, Eliane, José Paulo dos Reis, Mércio e o Pedrinho.

À divertida aluna de Iniciação Científica Suelen Cella, pela ajuda na realização de grande parte desse trabalho e por ter me ensinado coisas que eu julgava saber.

Ao sempre bem humorado e alegre Douglas, pelo preparo das soluções reveladoras usadas em microscopia.

Ao SDO/FOUSP, pela formatação e revisão do texto.

Pesquisa financiada pelo CNPq (141651/2004-0), CAPES- ProAp, e FAPESP $(03 / 12961-3)$ e $(2005 / 01365-6)$. 
Bauer JRO. Propriedades mecânicas do titânio comercialmente puro e da liga Ti-6Al4V fundidos em diferentes ambientes [Tese de Doutorado]. São Paulo: Faculdade de Odontologia da USP; 2007.

\section{RESUMO}

Problema: O emprego do titânio e ligas de titânio para aplicações médicas e odontológicas tem aumentado nas últimas décadas, porém, o alto custo do material desestimula o seu uso rotineiro. Objetivos: Avaliar o efeito da pureza do argônio nas propriedades mecânicas, microestrutura e modo de fratura do titânio comercialmente puro (Grau I) e da liga Ti-6Al-4V. Material e Métodos: As fundições para cada liga foram realizadas em uma máquina de indução eletromagnética com um argônio de alta pureza $(99,999 \%)$ e um argônio conhecido como industrial $(99,98 \%)$. Os testes de resistência à tração, limite de proporcionalidade e alongamento foram realizados em máquina de ensaio universal sob velocidade de $1 \mathrm{~mm} / \mathrm{min}$. Os espécimes fraturados foram embutidos em resina fenólica (baquelite) e polidas para a realização da microdureza Vickers (100g/15s), a a 25, 50, 100, 200 e 500 $\mu$ m da borda do corpo-de-prova. A microestrutura das ligas também foi analisada em alguns espécimes, com o objetivo de avaliar a superfície fraturada dos espécimes alguns foram submetidos à microscopia eletrônica de varredura. Análise estatística: Os dados provenientes de cada teste mecânico foram submetidos a uma análise de variância (tipo de titânio vs. pureza do argônio) e teste de Tukey $(\alpha=0,05)$. Os dados de microdureza Vickers foram submetidos a uma análise de variância de medidas repetidas (fatores principais: liga e argônio) e medida repetida: distância e teste de Tukey para o contraste entre médias $(\alpha=0,05)$. Resultados: O grau de 
pureza do gás não influenciou os valores do limite de proporcionalidade, da resistência à tração e alongamento, assim como a microdureza Vickers, microestrutura e padrão de fratura. A liga Ti-6Al-4V apresentou alto valores de resistência à tração, limite de proporcionalidade e microdureza Vickers, e baixo alongamento. A microdureza dos materiais foi alta nas proximidades da borda, mas a pureza do argônio não teve influência alguma. Conclusões: O argônio industrial pode ser utilizado para realizar as fundições do Ti CP e Ti-6Al-4V sem prejuízos nas suas propriedades.

Palavras-Chave: Titânio, Propriedades mecânicas, Resistência à tração, Teste de dureza, Argônio, Técnica de fundição Odontológica 
Bauer JRO. Mechanical properties of commercially pure titanium and Ti-6Al-4V alloys casting in different environments [Tese de Doutorado]. São Paulo: Faculdade de

Odontologia da USP; 2007.

\section{ABSTRACT}

Background: Although CP titanium and titanium alloys have been used for medical and dental applications, their high cost has not stimulated their current use. Objective: The purpose of this study was to evaluate the effect of argon purity on the mechanical properties, microstructure and fractography of CP Ti (Grade I) and Ti-6Al$4 \mathrm{~V}$ cast alloys. Material and Methods: The castings for each alloy were made in a centrifugal casting machine using either a high-purity (99.999\%) and or an industrial argon gas (99.98\%). The ultimate tensile strength (UTS), proportional limit (PL) and elongation (EL) were evaluated in a universal testing machine at a crosshead speed of $1 \mathrm{~mm} / \mathrm{min}$. The fractured specimens were embedded in phenolic resin and polished down for Vicker's microhardness (VHN) measurement (100g, 15s) from 25 $\mu \mathrm{m}$ below the cast surface, then at $50 \mu \mathrm{m}, 100 \mu \mathrm{m}, 200 \mu \mathrm{m}$ and $500 \mu \mathrm{m}$. The microstructures of the alloys were also revealed. Scanning electron microscopy fractography was undertaken for the fractured surfaces after tensile testing. The data from the mechanical tests and hardness were subjected to a two-way ANOVA and Tukey's test $(\alpha=0.05)$. Results: The mean values of UTS, PL, EL and VHN were not affected by the argon gas purity. Higher UTS, PL and VHN and lower EL was observed for Ti-6Al-4V. The microhardness values of both alloys were higher at the surface layers and it was not influenced by the argon gas purity. Conclusions: It was 
concluded that the industrial argon gas can be safely used to cast CP Ti and Ti-6Al$4 \mathrm{~V}$, since it does not alter the mechanical properties of the studied alloys.

Keywords: Titanium, Mechanical properties, Tensile strength, Hardness test, Argon, Dental casting technique. 


\section{SUMÁRIO}

1 INTRODUÇÃO 13

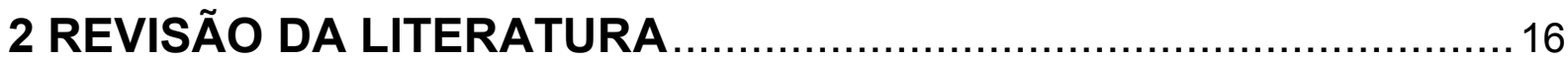

3 PROPOSIÇÃO

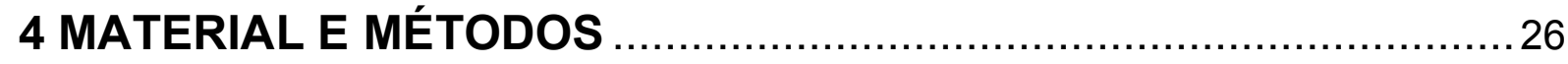

5 RESULTADOS

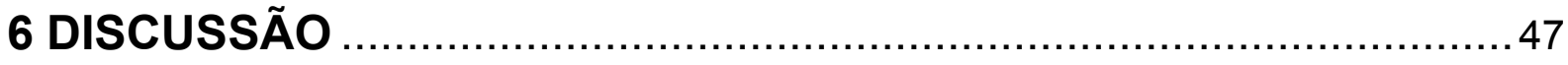

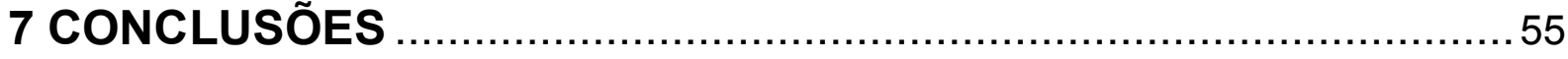

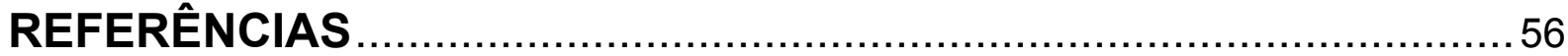




\section{INTRODUÇÃO}

Algumas crises internacionais, iniciadas na década de 30 , estimularam a procura por ligas alternativas às de ouro, dentre as quais se destacavam as ligas de Níquel-Cromo (Ni-Cr) pela sua diversidade de uso (WATAHA, 2002).

Porém, as ligas de Ni-Cr estão sob constante investigação devido às reações biológicas adversas que podem desencadear (WATAHA, 2000). Elementos químicos que compõem essas ligas, como cobalto, molibdênio, alumínio, cromo e especialmente o níquel, podem ser causa de reações alérgicas (BRENDLINGER; TARSITANO, 1970; FENTON; JEFFREY, 1978; HUBLER e HUBLER, 1983; HILDEBRAND et al., 1989; HABERMAN; PRATT; STORRS, 1993; BEZZON, 1993; KONONEN et al., 1995; AL-WAHEIDI, 1995).

Entretanto vale lembrar que, além das ligas de metais básicos, vários estudos também relatam respostas alérgicas a ligas de metais nobres contendo ouro (FREGERT; KOLLANDER; POULSEN, 1979; SHEPARD et al., 1983; TSURUTA et al., 2001; AHNLIDE et al., 2002; MOLLER, 2002).

O titânio apresenta sucesso bem documentado a longo prazo como um biomaterial usado em implantes dentários. Assim sendo, o emprego do titânio na Odontologia vem aumentando consideravelmente devido principalmente a sua biocompatibilidade, alta resistência à corrosão, baixa densidade, alta resistência mecânica, alta ductibilidade (WANG; FENTON, 1996). O titânio, além dessas características, ainda é um metal que apresenta a metade da densidade de ligas como Co-Cr e Ni-Cr, é radiolúcido (o que permite o controle de porosidades), de baixo custo e de preço estável (COLLINGS, 1984; OKABE; HERØ, 1995). 
Por outro lado, o uso do titânio em aparelhos protéticos, obtidos por meio de fundições, tem se mostrado problemático, devido a algumas características: alto ponto de fusão $\left(1670 \pm 50^{\circ} \mathrm{C}\right)$, baixa densidade que dificulta a injeção no molde, alta reatividade com componentes do cadinho e do revestimento fosfatado, particularmente com $\mathrm{SiO}_{2}$, e ainda com gases do ambiente como oxigênio, hidrogênio, nitrogênio e carbono (OKABE; HERØ, 1995). Por isso são necessárias técnicas complexas e equipamentos especiais para fundição, que aumentam o custo do processo (BAUER et al., 2002).

Em virtude da impossibilidade do uso de óxidos convencionais para a expansão do revestimento, como aqueles contendo sílica, é indispensável o emprego de revestimento com óxidos especiais para expansão, o que também eleva o custo do procedimento (TAKAHASHI et al., 1990).

Nos últimos anos, um número crescente de pesquisas vem sendo direcionado para analisar as particularidades da fundição com o titânio, sempre com interesse em aprimorar a técnica e para torná-lo um substituto vantajoso às ligas convencionais. Meloncini, em 2000, obteve sucesso com um método que diminuiu a quantidade de revestimento especial utilizado na técnica de fundição. Outra abordagem estudada para reduzir os custos, foi a de diluir o líquido especial empregado no revestimento (WALDEMARIN et al., 2000).

Devido às características de reatividade do titânio, recomenda-se que a fundição seja realizada em ambiente controlado por um gás inerte, como o hélio ou argônio (CRAIG; POWERS, 2002). É importante considerar que o argônio disponível no mercado é oferecido em diferentes graus de pureza com diferentes custos, e que, até hoje, nenhum estudo foi realizado para avaliar o comportamento do titânio fundido em função da pureza do argônio utilizado, e sim, dos ciclos (TAJIMA et al., 
1994). Entretanto, diversos pesquisadores se preocupam com a qualidade do argônio empregado (KIKUCHI et al., 2003; AOKI et al., 2004; SATO et al., 2005; KOIKE et al., 2005).

As diferenças na composição do argônio têm uma influência no custo do produto final, principalmente quando se compara um argônio industrial, que pode apresentar valor até cinco vezes mais baixo em relação a um argônio mais puro, tornando-se uma alternativa para a redução dos custos. 


\section{REVISÃO DA LITERATURA}

Histórico

Um dos elementos da Tabela Periódica, descrito pelo reverendo inglês William Gregor no ano de 1791, possui número atômico 22, peso atômico 47,9 apresentando uma densidade de $4,51 \mathrm{~g} / \mathrm{cm}^{3}$ (60\% menor que o ferro), ponto de fusão da ordem de $1668^{\circ} \mathrm{C}$ e com uma estrutura cristalina hexagonal compacta (abaixo de $882,5^{\circ} \mathrm{C}$ ) e cúbica do corpo centrado (acima de $882,5^{\circ} \mathrm{C}$ ). Alguns anos depois, em 1795, o químico alemão Martin Klaproth encontrou esse elemento no minério rutílio $\left(\mathrm{TiO}_{2}\right)$, até então desconhecido, e denominou-o titânio.

Por ser um metal muito reativo, o titânio era de difícil obtenção, na forma pura, a partir do minério rutílio. Foi então que Wilhelm Kroll desenvolveu o processo de refino, sendo por isso considerado o pai da indústria do titânio.

O titânio é um metal relativamente novo para diversas aplicações. O interesse nesse metal hoje em dia, se deve em muito às suas excelentes propriedades e abundância. Este elemento é o quarto metal mais prevalente na terra, só perdendo para o alumínio, ferro e magnésio, e sua concentração na crosta terrestre gira em torno de $0,6 \%$.

Vale lembrar que, a sua grande presença na terra é maior do que diversos elementos usados na Odontologia, como o cromo, níquel, cobre e molibdênio (COLLINGS, 1984).

Titânio Comercialmente Puro 
O titânio conhecido como comercialmente puro (Ti CP) apresenta teores de pureza que estão entre 98 a 99,5\%. Suas propriedades físicas podem variar de acordo com a quantidade de impurezas, de elementos residuais ao processo de purificação, tais como: oxigênio $(\mathrm{O})$, ferro $(\mathrm{Fe})$, nitrogênio $(\mathrm{N})$, carbono $(\mathrm{C})$ e hidrogênio (H) (PÄßLER; MANN, 1991). As impurezas é que determinam a classificação dos quatro tipos de titânio denominados comercialmente puros. (WANG; FENTON, 1996).

Apesar da pequena quantidade de $\mathrm{O}, \mathrm{Fe}, \mathrm{N}, \mathrm{C}$ e H presentes no "titânio puro", consideráveis mudanças em algumas propriedades mecânicas ocorrerão, principalmente devido ao $\mathrm{O}$ e ao $\mathrm{Fe}$.

Isto porque, estes elementos passam a ocupar áreas dentro do arranjo cristalino (interstício) e causam desalojamento parcial dos átomos de titânio, o que acarreta num "travamento", diminuindo o eventual deslizamento dos átomos quando sujeitos a forças externas, aumentando desta forma a resistência a possíveis deformações plásticas.

O titânio e suas ligas têm seus arranjos cristalinos nas formas: hexagonal compacta, também chamada de fase alfa ( $\alpha$ ), cúbica de corpo centrado ou fase beta ( $\beta$ ), além da mistura das duas grades $\alpha$ e $\beta$ (COLLINGS, 1984).

O titânio puro apresenta-se na fase alfa abaixo de $882^{\circ} \mathrm{C}$. Acima dessa temperatura a estrutura cristalina modifica-se para cúbica de corpo centrado $(\beta)$, mas quando resfriado o titânio retorna a sua estrutura original (DONACHIE JR, 1988).

Ligas de Titânio

A liga de titânio mais comumente encontrada e usada é a Ti-6AL-4V (6\% de 
alumínio e $4 \%$ de vanádio) devido às suas excelentes propriedades mecânicas (CRAIG; POWERS, 2002). Esta condição se deve a formação de duas fases, $\alpha$ e $\beta$, à temperatura ambiente, ao contrário do que ocorre com o titânio comercialmente puro. Estas fases podem ser observadas claramente na microestrutura da liga.

Assim, esta melhoria das propriedades se deve ao fato do alumínio (Al) ser um estabilizador da fase alfa e o vanádio (V) um estabilizador da fase beta, fazendo com que a liga apresente, na temperatura ambiente, ambas as fases (PARR; GARDNER; TOTH, 1985).

Apesar da concentração relativamente pequena de $\mathrm{Al}$ e $\mathrm{V}$ na liga Ti-6Al-4V, esta apresenta uma mudança drástica na resistência à fratura, limite de escoamento, dureza, microestrutura, padrão de fratura e alongamento. Entretanto, o módulo de elasticidade apresenta-se quase inalterado em relação ao titânio comercialmente puro (NIINOMI, 1998). Todas essas características fazem da Ti-6Al-4V, a liga $\alpha+\beta$ ser a mais estudada no momento, sendo também a mais indicada para a fabricação de dispositivos protéticos onde é necessária alta resistência, em substituição ao titânio comercialmente puro (OKABE; HERØ, 1995).

Inúmeros estudos demonstram o excelente desempenho mecânico desta liga quando comparada ao titânio puro e a ligas experimentais (KOIKE et al., 2005; LIN; JU; CHERN LIN, 2005; ROCHA et al., 2005). Em relação ao titânio puro, a liga Ti6Al-4V apresenta quase o dobro de resistência à tração e da dureza (KIKUCHI et al., 2003; AOKI et al., 2004). Vale lembrar que, quanto a resistência à tração, a liga Ti$6 \mathrm{Al}-4 \mathrm{~V}$ apresenta uma grande similaridade com as ligas a base de $\mathrm{Ni}-\mathrm{Cr}$ e $\mathrm{Co}-\mathrm{Cr}$ (BAUER et al., 2006)

Em relação às ligas de $\mathrm{Ni}-\mathrm{Cr}$ e $\mathrm{Co-Cr}$, o titânio $\mathrm{CP}$ e a liga Ti-6Al-4V apresentam como vantagem principal, a baixa densidade que acarreta redução do 
peso da peça protética e aumenta o conforto do portador (THOMAS; LECNER; MORI, 1997).

Quanto a biocompatibilidade, da mesma forma que acontece com as ligas de $\mathrm{Ni}-\mathrm{Cr}$ e Co-Cr, o uso da liga Ti-6Al-4V vem sendo questionado por alguns pesquisadores. Durante seu uso, íons de V e de Al podem ser liberados e esses são apontados como elementos de alta toxicidade, sendo o alumínio associado ao mal de Alzheimer. Além disso, esses íons podem ocasionar descamação da mucosa do trato respiratório e ainda prejudicar a produção sanguínea. Isto pode ser agravado pela diminuição da resistência à corrosão da liga quando exposta por muito tempo aos fluidos corpóreos (KOBAYASHI et al., 1998; SHUKLA; BALASUBRAMANIAM; BHARGAVA, 2005; OKAZAKI; GOTOH, 2005).

Há inúmeros elementos estabilizadores de fases que podem ser combinados com o titânio, os $\alpha$-estabilizadores mais usados são: Al, estanho (Sn), O e N. Já os $\beta$-estabilizadores encontrados com maior freqüência são: $V$, molibdênio (Mo), cobre (Cu), Fe, nióbio (Nb) e o tântalo (DONACHIE JR, 1988; OKABE; HERØ, 1995).

Sendo assim, vários pesquisadores buscam por elementos não tóxicos que substituam tanto o $\mathrm{Al}$ quanto $\circ \mathrm{V}$, mas que mantenham as excelentes propriedades mecânicas da liga Ti-6Al-4V (CAl et al., 2003).

$\mathrm{O} \mathrm{Nb}$, assim como o $\mathrm{V}$, é um $\beta$-estabilizador e se apresenta como uma boa alternativa, em função da sua resistência à corrosão. Assim, foi desenvolvida a liga Ti-6Al-7Nb, que apresentou resultados satisfatórios de biocompatibilidade a longo prazo (SEMLITSCH et al., 1992). Entretanto, o Al, como $\alpha$-estabilizador, continua como principal responsável pelo ganho em propriedades mecânicas da liga Ti-6Al4V em relação ao titânio CP (KHAN; WILLIAMS; WILLIAMS,1999).

Uma outra liga que pode ser considerada é a Ti-13Nb-13Zr, que têm o nióbio 
como estabilizador de fase alfa, e o zircônio $(\mathrm{Zr})$, que é um elemento isomorfo, ou seja, estabiliza tanto a fase alfa ou beta (DONACHIE JR, 1988). Entretanto, esta liga tem como principal indicação os implantes dentários, devido ao baixo módulo de elasticidade (LIN; JU; CHERN LIN, 2005).

Diversas ligas experimentais de titânio têm sido propostas, com boas perspectivas para serem usadas como peças metálicas fundidas, como as ligas de Ti-Cu, Ti-Hf e Ti-Nb (LEE; JU; CHERN LIN, 2002; KIKUCHI et al., 2003; SATO et al., 2005).

Fundição

Nas últimas décadas, muitos estudos relativos às particularidades do processo de fundição do titânio e de suas ligas vêm sendo realizados com o objetivo de aperfeiçoar a técnica e diminuir os custos.

É sabido que diversos são os fatores que dificultam o processo de fundição. A baixa densidade do titânio e de suas ligas, alta temperatura de fusão, alta reatividade química, com elementos do revestimento e gases da atmosfera, e a necessidade de equipamentos especiais, por exemplo, fazem a sua fundição especialmente trabalhosa e onerosa (TAIRA; MOSER; GREENER, 1989).

Outra desvantagem apresentada pelas ligas de titânio é o alto intervalo de fusão $\left(1668^{\circ} \mathrm{C}-1760^{\circ} \mathrm{C}\right)$, que requer equipamentos especiais como a fonte de calor, sendo então utilizados a indução eletromagnética ou o arco voltáico (VOITIK,1991).

Além disso, quando aquecido a altas temperaturas, especialmente acima de $600^{\circ} \mathrm{C}$, o titânio passa a ser extremamente reativo, sendo ávido por gases como $\mathrm{O}$, H e nitrogênio (VOITIK,1991). Por esse motivo, foram desenvolvidos equipamentos 
que mantém o titânio, durante o processo de fundição, em ambiente livre de oxigênio (vácuo) ou sob presença de gases inertes. A não observância destes cuidados leva à contaminação do titânio líquido (fundido) e a um aumento considerável do risco de explosão durante o processo de fundição (BAUER et al., 2002).

Apesar do alto custo dos demais gases nobres, um estudo com argônio, hélio, xenônio e criptônio mostra que há uma diminuição significante na quantidade de porosidades quando o xenônio e o criptônio são usados. Entretanto, nos testes mecânicos de fratura, os maiores valores de resistência foram obtidos com as fundições realizadas em ambiente preenchido com o gás hélio. Os melhores resultados, nas propriedades mecânicas proporcionados pelo uso do gás hélio, se devem ao seu menor raio atômico, que aumenta sua difusão relativa no titânio fundido, levando à formação de uma solução sólida intersticial, enquanto que a utilização de outros gases nobres, com maior raio atômico, conduz à solução substitucional (ZINELIS, 2000).

Uma alternativa ao emprego de gás nobre como controle do ambiente de fundição é a utilização de vácuo, em que pese haver algum risco de explosão tornase uma alternativa interessante. Tajima, em 1994 avaliou a microdureza do titânio fundido em atmosfera controlada por argônio ou apenas sob vácuo, e os seus resultados não demonstraram diferença na microdureza da peça fundida. Portanto, de certa forma, isso demonstra o sucesso desta técnica, apesar de ocorrer aumento na concentração de oxigênio no interior da câmara de fundição que poderia ocasionar uma considerável contaminação na peça do titânio fundido (TAJIMA et al, 1994).

Por outro lado, os valores de pressão de injeção do argônio para a limpeza da câmara e injeção do metal líquido, devem ser observados. Valores altos da 
pressão de injeção do gás podem ajudar na redução do nível de impurezas e ganho de força de injeção.

Contudo, pressão de injeção muito alta (300-450 torr) conduz a um maior grau de porosidades e propriedades mecânicas inferiores quando comparados a menores valores de pressão (50-150 torr), devido ao turbilhonamento do líquido, e conseqüentemente à incorporação de gases no metal (WATANABE et al., 1997).

Os estudos que comparam os diferentes sistemas de injeção de liga fundida sempre se baseiam no controle das porosidades induzidas dentro da massa do material. Basicamente três fenômenos podem ocorrer durante o processo de fundição, que explicam o surgimento de porosidades no interior das peças fundidas: (1) quando a diferença de pressão entre a câmara de fundição e a câmara do molde é demasiadamente elevada, ocorre a inclusão de gases; (2) quando a velocidade de injeção é muito alta, há severa turbulência no metal, produzindo um canal vazio no interior da peça fundida; (3) pelo resfriamento brusco do metal, pois a porção que atinge o final do molde em primeiro lugar solidifica-se prematuramente, impedindo que o "vácuo" promova o escape de gases pelas porosidades do revestimento. Estes fatos podem comprometer o preenchimento total do molde (WATANABE et al., 1997), exceto se for usada maior quantidade de sprue e canais de ventilação (vents). Com tais modificações na técnica é possível minimizar a pressão de retorno dos gases, facilitando o preenchimento completo do molde pela liga e melhorando a adaptação da peça (HERØ; SYVERUD; WAARLI, 1993, CHAN et al., 1998, LEAL et al., 2006).

Outra dificuldade encontrada na fundição do titânio é a sua instabilidade sob altas temperaturas. Além de reagir com alguns gases da atmosfera, o titânio é capaz de reagir também com os componentes do cadinho cerâmico e do revestimento 
(SYVERUD; OKABE; HERØ, 1995).

A facilidade de reduzir vários óxidos leva o titânio a formar vários compostos com a sílica $\left(\mathrm{SiO}_{2}\right)$. Como resultado, uma extensa camada de contaminação é observada quando utilizamos revestimentos a base de $\mathrm{SiO}_{2}$ (revestimentos fosfatados). Esta contaminação traz diversas modificações e uma nova formação de microestrutura, diminuindo sensivelmente a resistência à corrosão e as propriedades mecânicas (PAPADOPOULOS; ZINELIS; VARDAVOULIAS, 1999).

Durante os últimos anos, um esforço tem sido realizado para encontrar um substituto para os revestimentos a base de $\mathrm{SiO}_{2}$. Para isso foram desenvolvidos revestimentos a base de Magnésio e Zr, óxidos inertes ao titânio, em lugar dos instáveis óxidos de Si e fósforo (SYVERUD; OKABE; HERØ, 1995; HUNG et al., 2004). Apesar destes óxidos não contaminarem o titânio, eles não apresentam boa combinação de propriedades como: coeficiente de expansão, permeabilidade para escape de gases e propriedades mecânicas (PAPADOPOULOS; ZINELIS; VARDAVOULIAS, 1999).

Entretanto, revestimentos a base de $\mathrm{Mg}$ e $\mathrm{Zr}$ apresentam bons resultados quanto à adaptação marginal e baixos valores de dureza na interface devido a baixa reação com o metal (HUNG et al., 2004). Porém, estes óxidos responsáveis pela expansão apresentam um alto custo em relação à tradicional sílica (PAPADOPOULOS; ZINELIS; VARDAVOULIAS, 1999).

Resumindo, a sílica, bastante utilizada como refratário da maioria das fundições com os mais diversos metais, atinge uma ótima expansão, compatível com o uso do titânio, porém, com alta reatividade. Por outro lado, se o refratário for à base $\mathrm{Mg}$ ou $\mathrm{Zr}$, tanto a reatividade com o titânio quanto a expansão alcançada serão baixas (HSU et al., 2005). 
Diante de todas estas considerações, os trabalhos com o titânio se tornam desafiadores, principalmente aqueles que de certa forma procuram a redução dos custos. 


\section{PROPOSIÇÃO}

O objetivo do presente estudo foi o de avaliar a influência do grau de pureza do argônio nas propriedades mecânicas do Ti CP e da liga Ti-6Al-4V. 


\section{MATERIAL E MÉTODOS}

A composição do titânio comercialmente puro (ASTM Grau I, Dentaurum, Alemanha) e da liga Ti-6Al-4V (Camacam, Brasil), empregados no presente estudo estão descritos na Tabela 4.1.

TABELA 4.1 - Composição dos materiais usados neste estudo

\begin{tabular}{lcccccccc}
\hline \multicolumn{7}{c}{ LIMITES MÁXIMOS DE IMPUREZA (\% PESO) } \\
\hline Material & $\mathbf{N}$ & Fe & $\mathbf{O}$ & $\mathbf{C}$ & $\mathbf{H}$ & $\mathbf{A l}$ & $\mathbf{V}$ \\
\hline Ti CP & 0,03 & 0,2 & 0,18 & 0,1 & 0,015 & & - \\
\hline Ti-6Al-4V & 0,009 & 0,21 & - & 0,026 & & 6,15 & 4,08 \\
\hline
\end{tabular}

Preparo dos corpos-de-prova

Os padrões de fundição em cera (P-Oclusal, Brasil) foram obtidos a partir de uma matriz metálica, com forma e dimensão ilustrada na Figura 4.1.

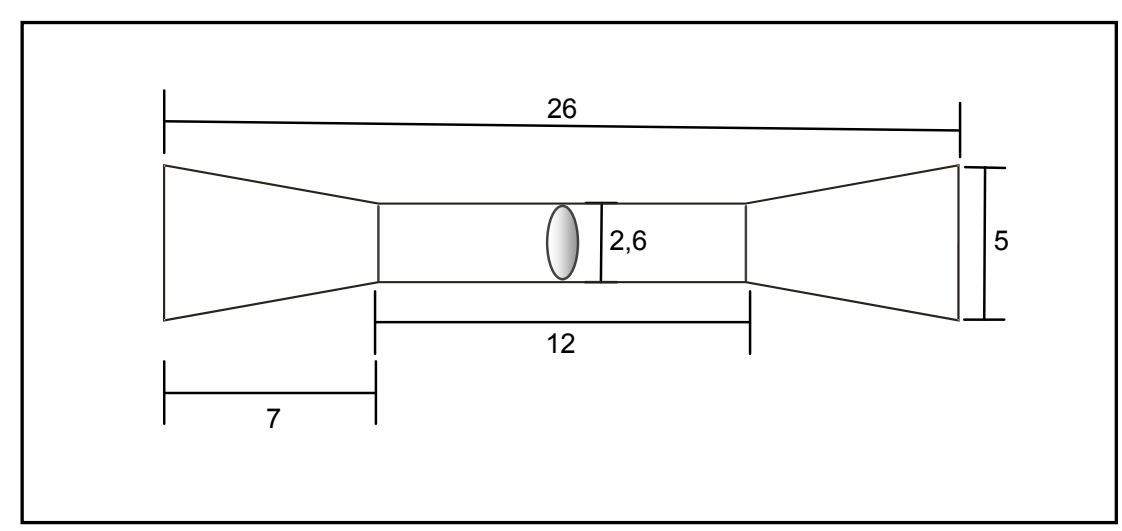

Figura 4.1 - Formato e dimensões dos corpos-de-prova utilizados neste estudo. Medidas em $\mathrm{mm}$

Um total de 6 fundições foi realizado para cada condição experimental. Dentro de cada um dos anéis de fundição foram incluídos 4 corpos-de-prova (cp) em cera. (Figura 4.2). 


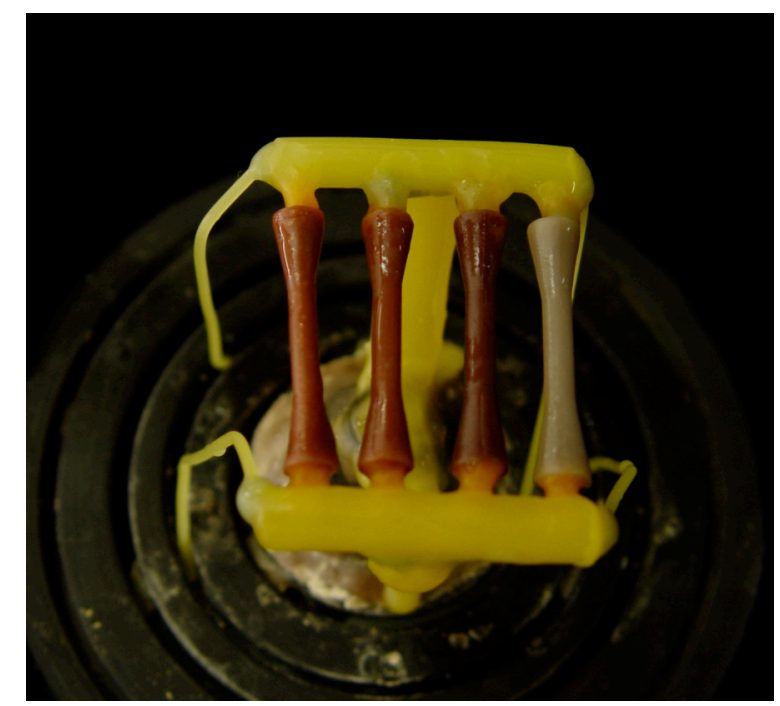

Figura 4.2 - Cp em cera, com as dimensões pré-determinadas durante o processo de montagem dos padrões para a realização da fundição

Para minimizar as distorções, os padrões de cera foram incluídos imediatamente em revestimento Rematitan Ultra (Dentaurun, Alemanha). A seguir, os anéis foram submetidos aos ciclos térmicos recomendados pelo fabricante: aquecimento de $5^{\circ} \mathrm{C} / \mathrm{min}$ a partir da temperatura ambiente até $250^{\circ} \mathrm{C}$, permanência à temperatura alcançada por $90 \mathrm{~min}$, aquecimento de $5^{\circ} \mathrm{C} / \mathrm{min}$ até $870^{\circ} \mathrm{C}$, permanência por $20 \mathrm{~min}$, resfriamento na velocidade de $7^{\circ} \mathrm{C} / \mathrm{min}$ até $430^{\circ} \mathrm{C}$ e permanência na temperatura obtida por pelo menos 60 minutos.

As fundições foram feitas em centrífuga com fonte de calor por indução eletromagnética (F.lli Manfredi, Itália). Para o controle do ambiente foram utilizadas duas composições de argônio, cujos limites de impurezas estão apresentados na Tabela 4.2.

Tabela 4.2: Limites de impurezas encontradas no argônio

\begin{tabular}{clccccc}
\hline $\begin{array}{c}\text { Argôni } \\
\mathbf{0}\end{array}$ & $\begin{array}{c}\text { Purez } \\
\mathbf{a}\end{array}$ & $\mathrm{THC}^{*}$ & $\mathbf{O}_{\mathbf{2}}$ & $\mathbf{C O} \mathbf{C O}_{\mathbf{2}}$ & $\mathbf{H}_{\mathbf{2}} \mathbf{O}$ & $\mathbf{N}_{\mathbf{2}}$ \\
\hline \multirow{2}{*}{$\mathrm{N}-50$} & 99,99 & $<0,5$ & $<1$ & $<0,5$ & & $<3$ \\
\hline Industri & $9 \%$ & $\mathrm{ppm}$ & $\mathrm{ppm}$ & $\mathrm{ppm}$ & $<2 \mathrm{ppm}$ & $\mathrm{ppm}$ \\
al & 99,98 & & $<50$ & & & \\
\hline
\end{tabular}

Air Liquide do Brasil - * Conteúdo total de hidrocarbonetos 
Após as fundições, os corpos-de-prova foram separados dos canais de alimentação por meio de um disco de carborundum e jateados com alumina (50 um de diâmetro) para a remoção inicial do revestimento. A seguir, os $\mathrm{cp}$ foram lavados, imersos em água dentro de uma cuba ultrasônica (Thornton/T-14, Brasil) para remoção dos resíduos de revestimento. Logo após, o comprimento inicial (L0) de cada cp foi mensurado com o auxílio de um paquímetro digital (Mitutoyo, Japão). Os cp foram também identificados conforme pode ser visualizado na Figura 4.3.

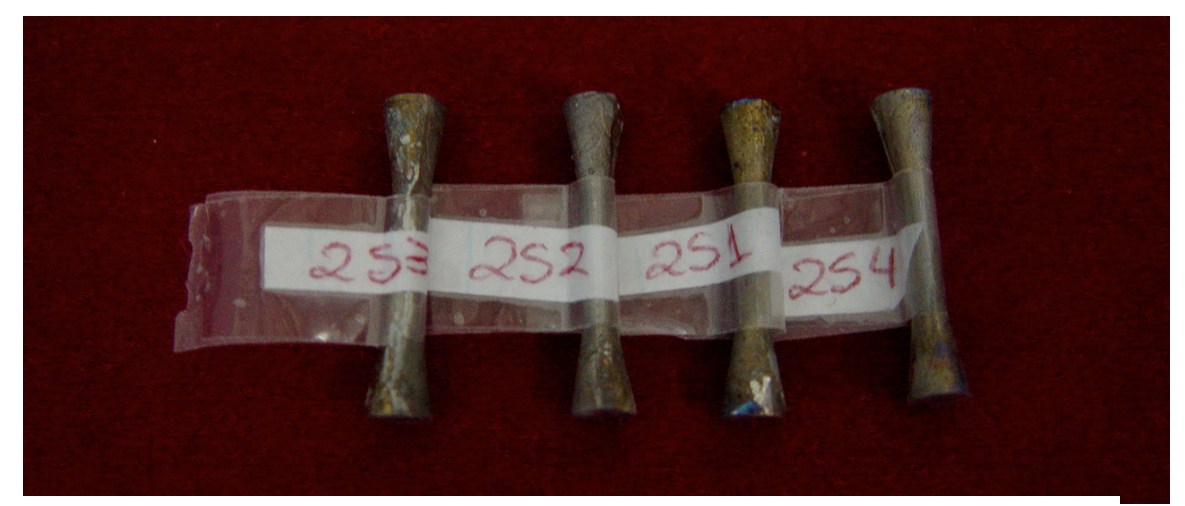

Figura 4.3 - Cp em metal, limpos e catalogados.

Os cp foram radiografados (CECCONI et al., 2002) para detecção de possíveis porosidades internas, sendo descartados aqueles que apresentavam defeitos (Figura 4.4).

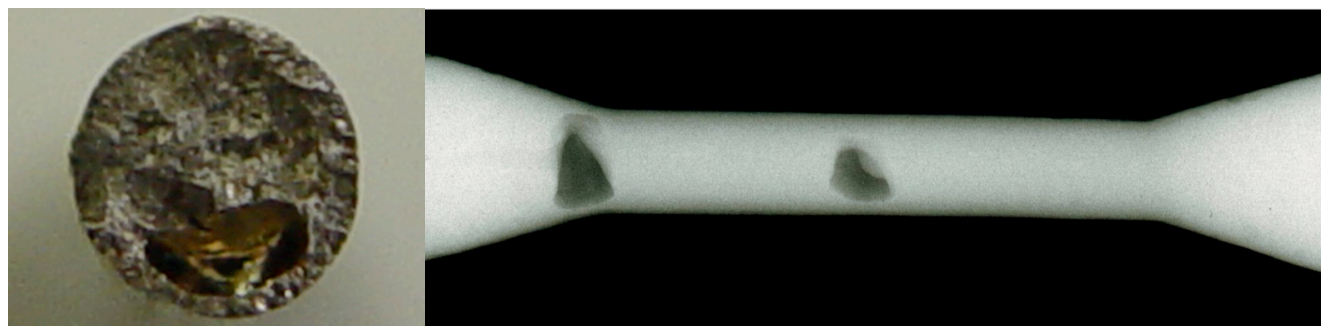

Figura 4.4 - Radiografia de um dos corpos-de-prova descartado por apresentar porosidades

Testes de tração 
Uma máquina para ensaios universal (Kratos, Brasil) foi usada para mensuração do limite de proporcionalidade e resistência à tração de cada um dos espécimes, à velocidade de $1 \mathrm{~mm} / \mathrm{min}$ (Figura 4.5).

Após a ruptura, os cp foram medidos com um paquímetro digital (Mitutoyo, Japão) para a obtenção do comprimento final (L). Com base nos dados do comprimento inicial (L0) e comprimento final (L) calculou-se o alongamento (\%) dos cp conforme fórmula abaixo:

$$
\text { Alongamento }=\left(\frac{L-L 0}{L 0}\right) \times 100
$$

onde:

$\mathrm{L}_{0}=$ Comprimento inicial do corpo-de-prova na distância entre garras antes o teste de resistência a tração.

$L=$ Comprimento final do corpo-de-prova.

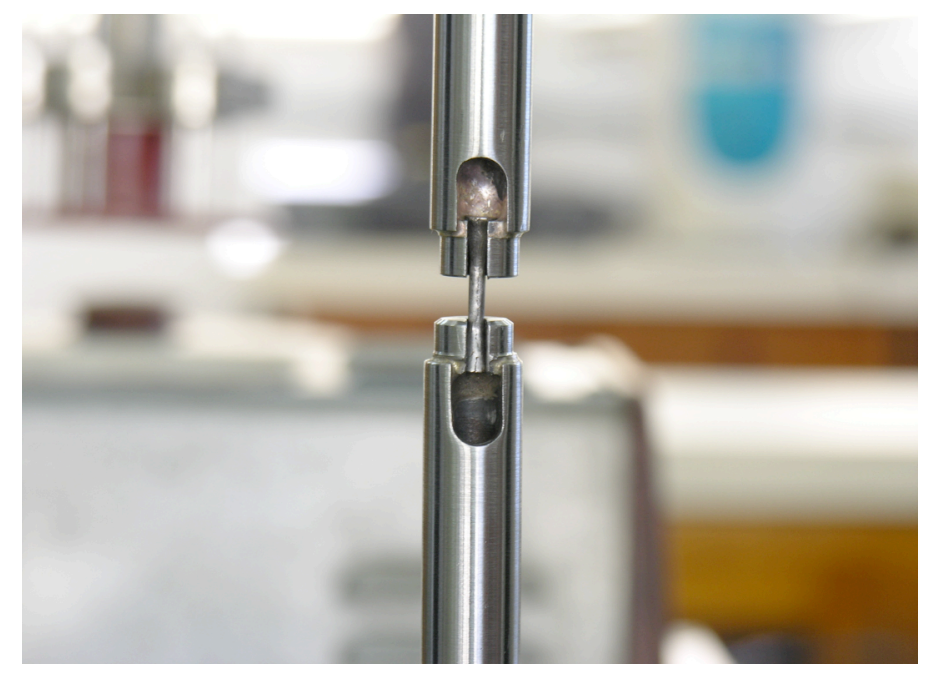

Figura 4.5 - Cp em posição para a realização do teste, onde foram obtidos os resultados de limite de proporcionalidade e resistência à tração

Os dados de alongamento, resistência à tração e limite de proporcionalidade foram submetidos a uma análise de variância de dois fatores (liga e pureza de argônio) e teste de Tukey para o contraste entre médias $(\alpha=0,05)$. Para estas 
propriedades foram sempre considerados os valores médios dentro de cada anel de fundição (Unidade experimental).

Teste de microdureza

O teste de microdureza Vickers foi realizado nos corpos-de-prova provenientes dos testes de resistência à tração. Os cp foram embutidos em resina baquelite (Buehler, EUA). Após o embutimento, os $\mathrm{cp}$ foram polidos até a lixa de carbureto de silício \#2000 (Norton, Brasil), e depois levados ao ultra-som durante 5 minutos para a remoção de contaminantes. A seguir, o polimento foi feito com um feltro (Struers, RØdovre, Dinamarca), pastas e soluções de diamante de 3 e $1 \mu \mathrm{m}$ (Struers, RØdovre, Dinamarca), e finalmente foi usada uma suspensão de sílica coloidal 0,05um (Struers, RØdovre, Dinamarca) diluída na proporção de 1:1 em água.

Cada cp foi levado ao microdurômetro HMV-2 (Shimadzu, Japão), e uma carga de $100 \mathrm{~g}$ foi aplicada por um período de $15 \mathrm{~s}$, para a mensuração da microdureza Vickers (AOKI et al., 2004). As medidas foram realizadas a $25 \mu \mathrm{m}$, $50 \mu \mathrm{m}, 100 \mu \mathrm{m}, 200 \mu \mathrm{m}$ e $500 \mu \mathrm{m}$ da borda do $\mathrm{cp}$, sendo realizadas duas mensurações em cada distância (Figura 4.6).

Os valores médios das duas leituras, de cada distância pré-determinada, de todos os cp de cada anel, foram utilizados para fins estatísticos.

Os dados de microdureza Vickers foram submetidos a uma análise de variância para medidas repetidas (distância), onde foram considerados fatores principais a liga e o argônio. Foi aplicado o teste de Tukey para o contraste entre médias $(\alpha=0,05)$. 


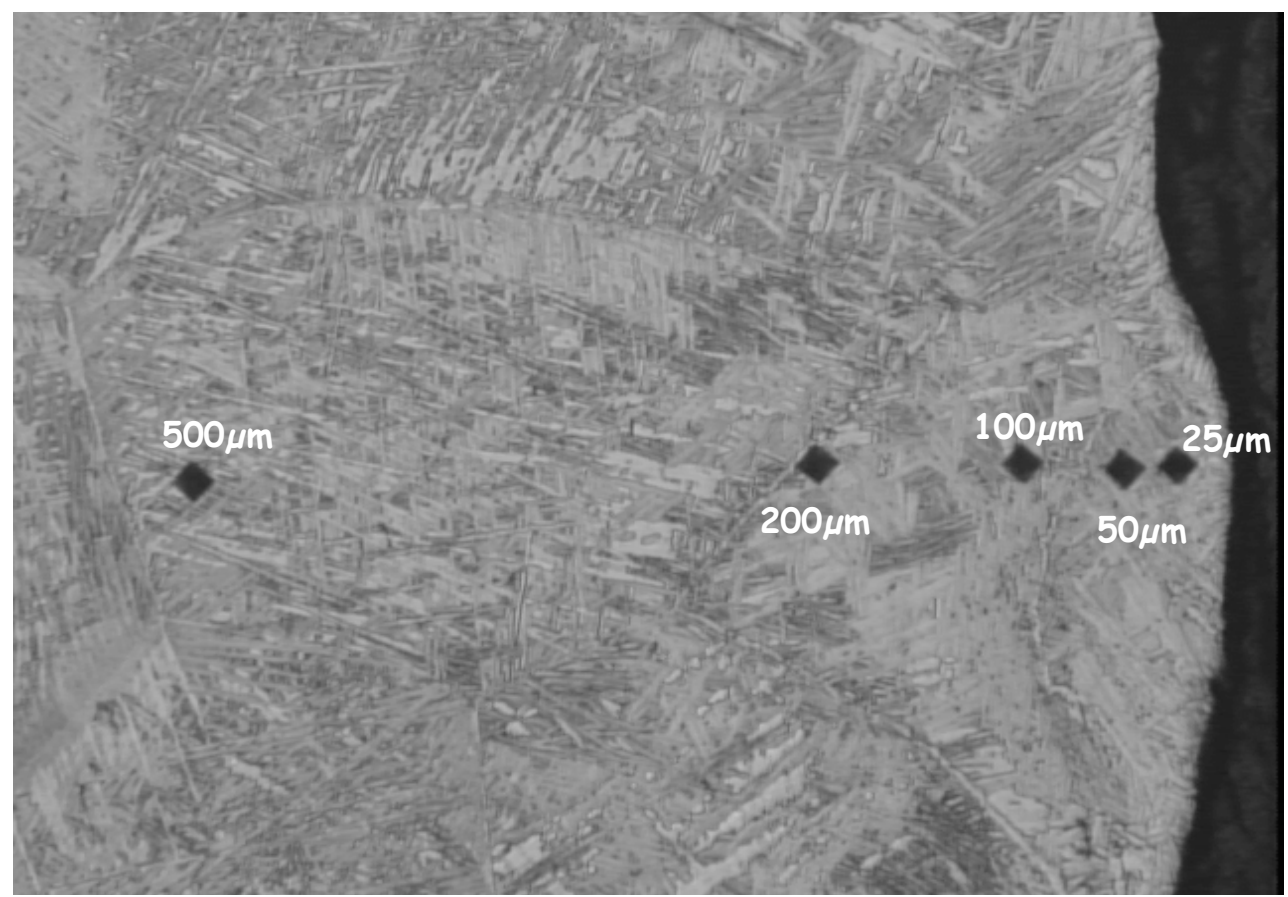

Figura 4.6 - Cp com as mensurações de dureza realizadas a $25 \mu \mathrm{m}, 50 \mu \mathrm{m}, 100 \mu \mathrm{m}, 200 \mu \mathrm{m}$ e $500 \mu \mathrm{m}$ de distância da borda

A análise da microestrutura, padrão de fratura e análise da composição dos elementos na superfície externa foi executada de forma qualitativa, apenas para caracterizar e/ou colaborar na explicação dos valores encontrados nos testes mecânicos.

\section{Microestrutura}

Após o término da mensuração da dureza, os espécimes foram atacados com reagente de Keller (2mL HF, $5 \mathrm{~mL} \mathrm{HNO} 3,3 \mathrm{~mL} \mathrm{HCl}$ e $190 \mathrm{~mL}$ de $\mathrm{H}_{2} \mathrm{O}$ deionizada) para evidenciar a microestrutura metálica. A superfície foi examinada em microscópio óptico e fotografada com 100 vezes de aumento (Shimadzu, Japão).

Microscopia Eletrônica de Varredura (Fractografia) e Leitura de Composição da Superfície (EDS) 
Antes de realizar a análise da superfície fraturada,, o cp foi lavado, imerso em água dentro de uma cuba ultrasônica (Thornton/T-14, Brasil), e seco em estufa a $37^{\circ} \mathrm{C}$ durante o período de 1 hora. Após isto, o cp foi examinado em um estereomicroscópio óptico (Olympus, SZX9, Japão), e em microscópio eletrônico de varredura (MEV, JEOL JSM 6300, Japão).

A microscopia eletrônica de varredura e espectroscopia de energia dispersiva (EDS) foi realizada na superfície de externa do $\mathrm{cp}$ no intuito de detectar possíveis contaminantes. 


\section{RESULTADOS}

Limite de proporcionalidade

Os valores das médias e os respectivos desvios padrões do limite de proporcionalidade (MPa) estão apresentados na Tabela 5.1.

Tabela 5.1 - Médias e desvios padrões do limite de proporcionalidade (MPa) das diferentes condições experimentais

\begin{tabular}{ccc}
\hline \multirow{2}{*}{ Material } & \multicolumn{2}{c}{ Qualidade do Argônio } \\
\cline { 2 - 3 } Ti CP & $\mathrm{N}-50$ & Industrial \\
\cline { 2 - 3 } Ti-6Al-4V & $400,6 \pm 64,2$ & $451,0 \pm 89,9$ \\
& $850,0 \pm 72,9$ & $935,6 \pm 82,2$ \\
\hline
\end{tabular}

A análise de variância demonstrou que a interação dos fatores não foi significante $(p=0,59)$, assim como o fator principal qualidade do argônio $(p=0,06)$, apesar de que este valor demonstra uma tendência importante. Apenas o fator material foi estatisticamente significante $(p=0,00001)$. Desta forma, somente as médias e desvios padrões dos dois materiais estão apresentados na tabela 5.2. Pode-se observar que a média do limite de proporcionalidade para a liga de Ti-6Al$4 \mathrm{~V}$ foi mais que o dobro em relação ao Ti CP.

Tabela 5.2 - Médias e desvios padrões do limite de proporcionalidade (MPa) para os dois materiais testados

\begin{tabular}{ccc}
\hline & \multicolumn{3}{c}{ Material } \\
\cline { 2 - 3 } Média \pm DP & Ti CP & Ti-6Al-4V \\
\cline { 2 - 3 } & $425,8 \pm 77,1$ & $892,8 \pm 77,6$ \\
\hline
\end{tabular}


Resistência à Tração

As médias e os respectivos desvios padrões de resistência à tração (MPa) estão apresentados na Tabela 5.3.

Tabela 5.3 - Médias e desvios padrões de resistência à tração (MPa) para as diferentes condições experimentais

\begin{tabular}{ccc}
\hline \multirow{2}{*}{ Material } & \multicolumn{2}{c}{ Qualidade do Argônio } \\
\cline { 2 - 3 } Ti CP & $\mathrm{N}-50$ & Industrial \\
\cline { 2 - 3 } Ti-6Al-4V & $476,4 \pm 64,5$ & $486,7 \pm 86,9$ \\
& $898,8 \pm 83,4$ & $975,1 \pm 94$ \\
\hline
\end{tabular}

A análise de variância demonstrou que a interação dos fatores $(p=0,34)$ assim como o fator qualidade do argônio $(p=0,22)$ não foram significantes. Apenas o fator material foi significante $(p=0,00001)$. Desta forma, na tabela 5.4 estão apresentadas apenas as médias e desvios padrões referentes a esse fator. Pode-se observar que a média de resistência à tração para a liga de Ti-6Al-4V foi significantemente superior à apresentada pela liga Ti CP.

Tabela 5.4 - Médias e desvios padrões da resistência à tração (MPa) dos materiais testados

\begin{tabular}{ccc}
\hline & \multicolumn{3}{c}{ Material } \\
\cline { 2 - 3 } Média \pm DP & Ti CP & Ti-6Al-4V \\
\cline { 2 - 3 } & $481,6 \pm 75,7$ & $937,0 \pm 88,7$ \\
\hline
\end{tabular}

Alongamento

As médias e os respectivos desvios padrões do alongamento (\%) estão apresentados na Tabela 5.5. 
Tabela 5.5 - Médias e desvios padrões do alongamento (\%) das diferentes condições experimentais

\begin{tabular}{ccc}
\hline \multirow{2}{*}{ Material } & \multicolumn{2}{c}{ Qualidade do Argônio } \\
\cline { 2 - 3 } Ti CP & $\mathrm{N}-50$ & Industrial \\
\cline { 2 - 3 } Ti-6Al-4V & $18,9 \pm 5,4$ & $16,7 \pm 4,2$ \\
& $2,1 \pm 1,0$ & $1,8 \pm 0,5$ \\
\hline
\end{tabular}

A análise de variância demonstrou que a interação dos fatores $(p=0,43)$ assim como o fator qualidade do argônio $(p=0,53)$ não foram estatisticamente significantes. Apenas o fator material apresentou significância estatística $(p=$ 0,00001). As médias e desvios padrões para os dois materiais testados estão apresentados na Tabela 5.6. Pode-se observar que a média de alongamento do metal Ti CP foi significantemente mais elevada que a da liga Ti-6Al-4V.

Tabela 5.6 - Médias e desvios padrões do alongamento (\%) dos materiais testados

\begin{tabular}{ccc}
\hline & \multicolumn{3}{c}{ Material $\left(^{*}\right)$} \\
\cline { 2 - 3 } Média \pm DP & Ti CP & Ti-6Al-4V \\
\cline { 2 - 3 } & $17,8 \pm 4,8$ & $1.9 \pm 0.7$ \\
\hline
\end{tabular}

A Figura 5.1 sumariza todos os dados médios das propriedades mecânicas avaliadas, ou seja, o limite de proporcionalidade, a resistência à tração e o alongamento. Este gráfico evidencia que a qualidade do argônio não afeta as propriedades mecânicas dos materiais, ao mesmo tempo em que, nitidamente demonstra a grande diferença entre os materiais. 


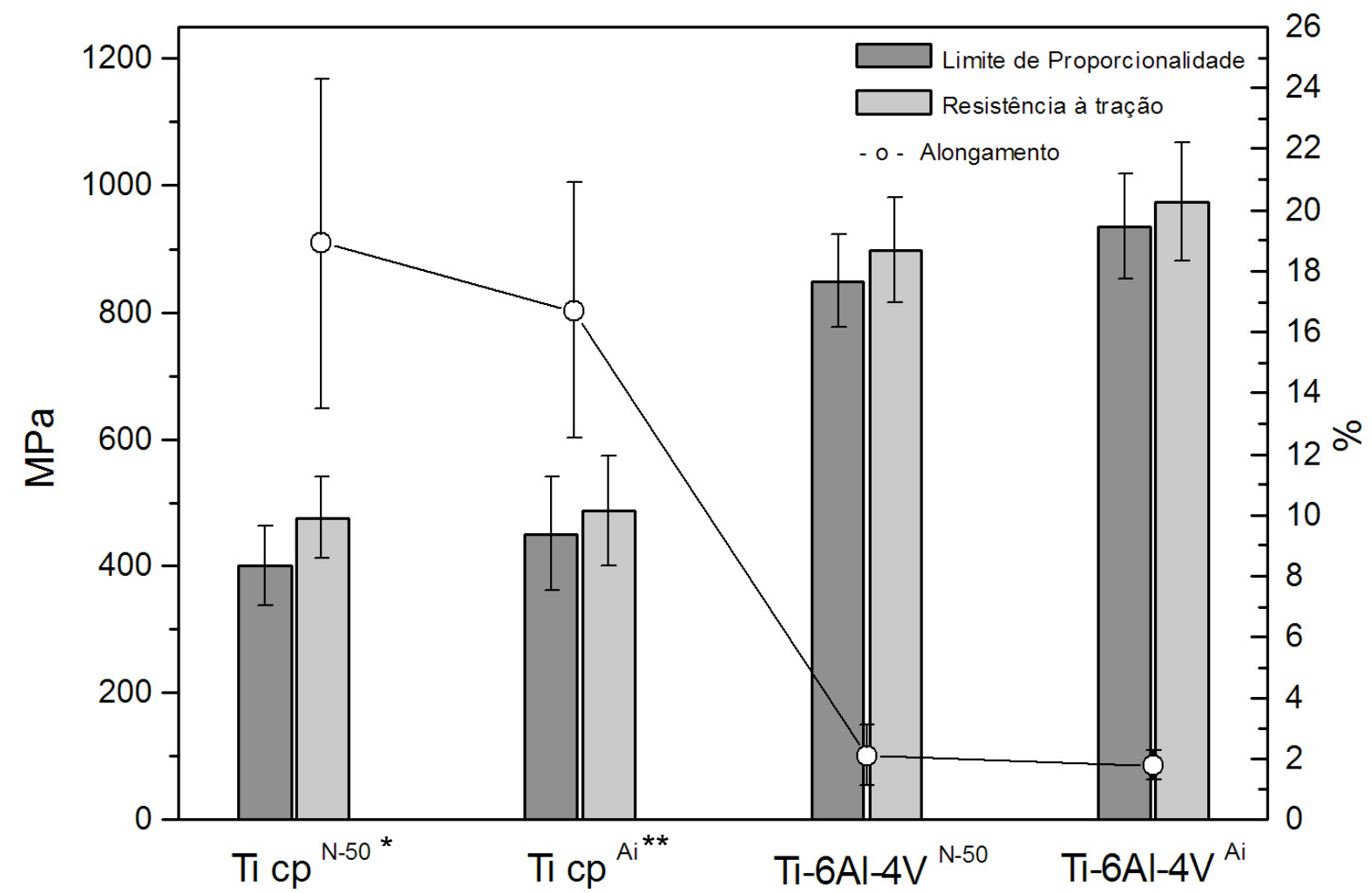

Figura 5.1 - Representação gráfica das médias e os correspondentes desvios padrões do alongamento, limite de proporcionalidade e resistência à tração das diferentes condições experimentais

* N-50 = Argônio 99,999\%

${ }^{* *} A i=$ Argônio 99,98\%

Microdureza

As médias e os respectivos desvios padrões de dureza Vickers para as diferentes condições experimentais estão apresentados na Tabela 5.7.

Tabela 5.7 - Médias e desvios padrões de dureza Vickers (HVN) das diferentes condições experimentais em diferentes distanciamentos da borda

\begin{tabular}{cccccc}
\hline \multirow{2}{*}{ Condições } & \multicolumn{5}{c}{ Distância da Borda ( $\boldsymbol{\mu m})$} \\
\cline { 2 - 6 } & 25 & 50 & 100 & 200 & 500 \\
\hline Ti CP/N-50 & $477,8 \pm 38,3$ & $390,0 \pm 54,5$ & $288,4 \pm 40,8$ & $208,2 \pm 39,1$ & $193,1 \pm 27,4$ \\
\hline Ti-6Al-4V/N-50 & $541,8 \pm 14,1$ & $452,9 \pm 13,8$ & $402,6 \pm 13,9$ & $373,3 \pm 13,0$ & $371,1 \pm 10,1$ \\
\hline Ti CP/Industrial & $505,4 \pm 16,6$ & $416,5 \pm 18,8$ & $319,0 \pm 23,5$ & $202,6 \pm 17,9$ & $180,5 \pm 22,6$ \\
\hline Ti-6Al-4V/Industrial & $575,2 \pm 27,3$ & $491,9 \pm 27,4$ & $414,4 \pm 23,5$ & $380,5 \pm 25,1$ & $371,2 \pm 22,8$ \\
\hline
\end{tabular}


A análise de variância demonstrou que as interações dos fatores Material vs. Distância da borda e Qualidade do argônio vs. Distância da borda foram significantes ( $p=0,00001$ e $p=0,03$, respectivamente). Também os fatores principais, Material e Distância da borda foram significantes $(p=0,008$ e $p=$ 0,00001, respectivamente). Desta forma, os valores foram novamente tabulados e estão apresentados nas tabelas 5.8 e 5.9.

$\mathrm{Na}$ tabela 5.10 , pode-se observar que a média para a liga de Ti-6Al-4V, como era de se esperar, foi significantemente maior que a obtida para o metal Ti CP.

Tabela 5.8 - Médias e desvios padrões de dureza Vickers (HVN) para as diferentes ligas testadas

Material

\begin{tabular}{lcc}
\cline { 2 - 3 } Média \pm DP & Ti CP & Ti-6Al-4V \\
\cline { 2 - 3 } & $318,2 \pm 30,0$ & $437,5 \pm 19,1$ \\
\hline
\end{tabular}

$\mathrm{Na}$ tabela 5.9, pode-se observar que as médias de dureza foram significantemente menores à medida que as mensurações foram realizadas afastando-se da borda, da superfície externa. Os valores mensurados em 25, 50 e $100 \mu \mathrm{m}$ foram estatisticamente semelhantes entre si e superiores aos mensurados a 200 e $500 \mu m$ da superfície.

Tabela 5.9 - Médias e desvios padrões de dureza Vickers (HVN) das distâncias testadas

\begin{tabular}{|c|c|c|c|c|c|}
\hline & \multicolumn{5}{|c|}{ Distância da Borda $(\mu \mathrm{m})$} \\
\hline & 25 & 50 & 100 & 200 & 500 \\
\hline Média \pm DP & $525,1 \pm 24,1^{a}$ & $437,8 \pm 28,6^{a}$ & $356,1 \pm 25,4^{a}$ & $291,1 \pm 23,8^{b}$ & $279,0 \pm 20,7^{b}$ \\
\hline
\end{tabular}

Na tabela 5.10, pode-se observar que o maior valor de dureza foi obtido com a liga Ti-6Al-4V na distância de $25 \mathrm{~mm}$ e o menor valor nas distâncias de 200 e 
$500 \mu \mathrm{m}$ para a liga de $\mathrm{Ti}$.

Tabela 5.10 - Médias e desvios padrões de dureza Vickers (HVN) das ligas nas diferentes distâncias testadas

\begin{tabular}{cccccc}
\hline \multirow{2}{*}{ Material } & \multicolumn{5}{c}{ Distância da Borda $(\boldsymbol{\mu m})$} \\
\cline { 2 - 6 } & 25 & 50 & 100 & 200 & 500 \\
\hline Ti CP & $491,6 \pm 27,5^{\mathrm{b}}$ & $403,3 \pm 36,6^{\mathrm{c}, \mathrm{d}}$ & $303,7 \pm 32,2^{\mathrm{e}}$ & $205,4 \pm 28,5^{\mathrm{f}}$ & \multirow{2}{*}{$186,8 \pm 25,0^{\mathrm{f}}$} \\
\hline Ti-6Al-4V & $558,5 \pm 20,7^{\mathrm{a}}$ & $472,4 \pm 20,6^{\mathrm{b}}$ & $408,5 \pm 18,7^{\mathrm{c}}$ & $376,9 \pm 19,1^{\mathrm{c}, \mathrm{d}}$ & \multirow{2}{*}{$371,2 \pm 16,4^{\mathrm{d}}$} \\
\hline
\end{tabular}

$\left(^{*}\right)$ Letras diferentes indicam grupos diferentes estatisticamente (Tukey $\left.\alpha=0,05\right)$.

$\mathrm{Na}$ tabela 5.11, pode-se observar que os valores de dureza foram mais influenciados pelo efeito da distância da superfície que pela Qualidade do argônio empregado na fundição.

Tabela 5.11 - Médias e desvios padrões de dureza Vickers (HVN) para a interação Qualidade de Argônio vs. diferentes distâncias testadas*

\begin{tabular}{cccccc}
\hline \multirow{2}{*}{$\begin{array}{c}\text { Qualidade do } \\
\text { argônio }\end{array}$} & \multicolumn{5}{c}{ Distância da Borda $(\boldsymbol{\mu m})$} \\
\cline { 2 - 6 } & 25 & 50 & 100 & 200 & 500 \\
\hline $\mathrm{N}-50$ & $509,8 \pm 26,2^{\mathrm{a}}$ & $421,4 \pm 34,1^{\mathrm{b}}$ & $345,5 \pm 27,3^{\mathrm{c}}$ & $290,7 \pm 26,0^{\mathrm{d}}$ & $282,1 \pm 18,8^{\mathrm{d}}$ \\
\hline Industrial & $540,3 \pm 22,0^{\mathrm{a}}$ & $454,2 \pm 23,1^{\mathrm{b}}$ & $366,7 \pm 23,5^{\mathrm{c}}$ & $291,6 \pm 21,5^{\mathrm{d}}$ & $275,8 \pm 22,7^{\mathrm{d}}$ \\
\hline
\end{tabular}

$\left.{ }^{*}\right)$ Letras diferentes indicam médias estatisticamente (Tukey $\left.\alpha=0,05\right)$. 
Figura 5.2 - Variação da média da microdureza Vickers da borda da superfície externa dos corposde-prova $(25 \mu \mathrm{m})$ até $500 \mu \mathrm{m}$ para as diferentes condições experimentais

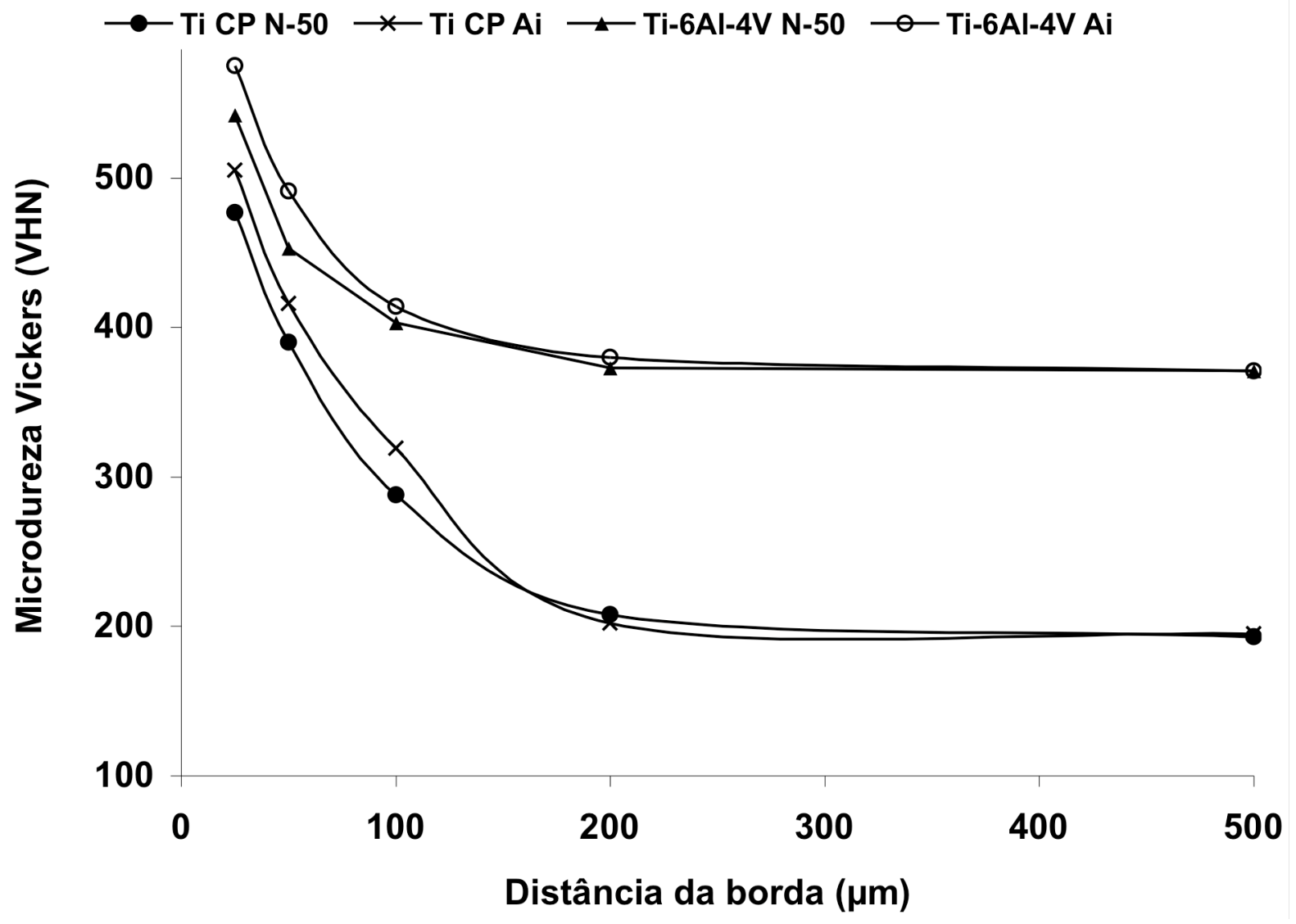

A Figura 5.2 sumariza os resultados de microdureza Vickers para as diferentes condições experimentais. Pode-se observar que a pureza do argônio utilizado praticamente não influencia as médias de dureza.

Microestrutura e Microscopia Eletrônica de Varredura (Fractografia)

Aparentemente, da mesma forma que as propriedades mecânicas, a microestrutura e o padrão de fratura não foram influenciados pela pureza do argônio. Diferenças estruturais significativas foram apenas observadas entre o Ti CP e a liga Ti-6Al-4V.

A Figura 5.3 mostra o titânio CP fundido nas diferentes condições com típica formação Widmanstätten, "basket-weave structure", com grandes grãos aciculares 
$\alpha-\mathrm{Ti}$.

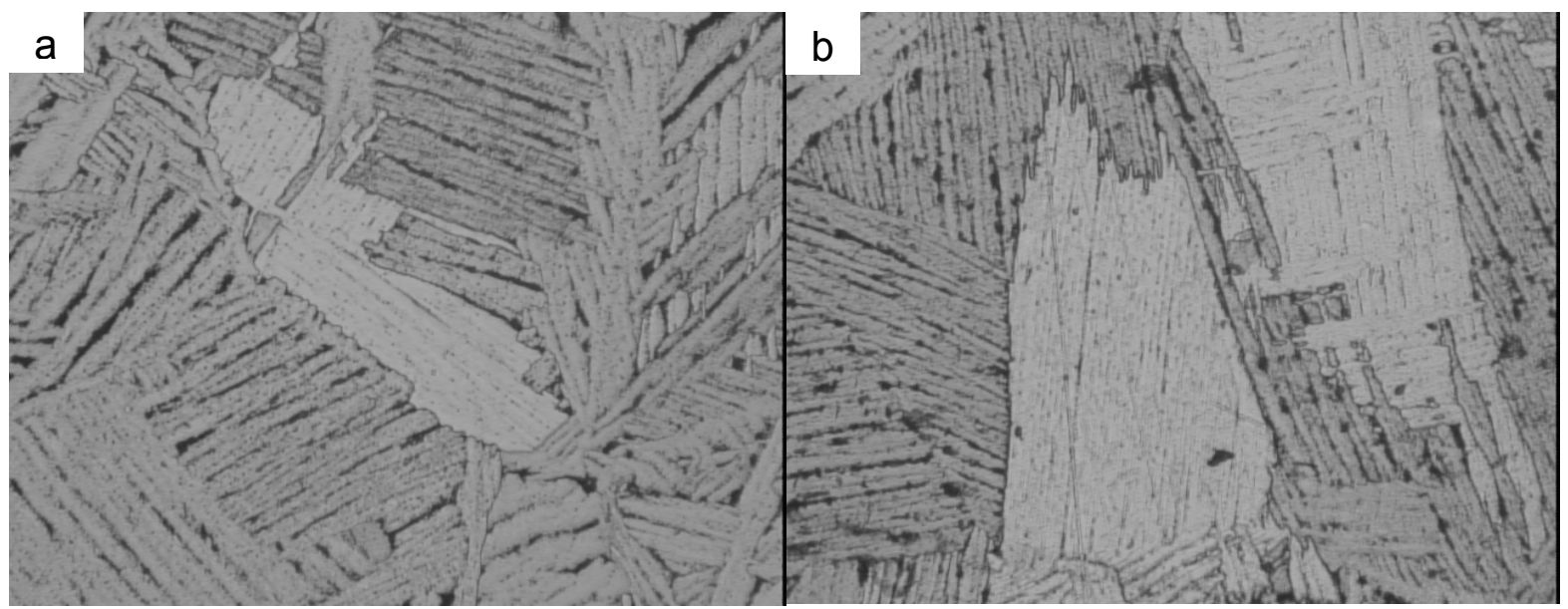

Figura 5.3 - Microestrutura óptica: (a) Titânio CP fundido em ambiente preenchido com o argônio N-50 e (b) Titânio CP fundido em ambiente preenchido com o argônio Industrial

A microscopia da liga Ti-6Al-4V fundida em diferentes ambientes mostra uma típica microestrutura Widmanstätten, onde as linhas finas escuras representam a fase $\beta$, e placas brancas aciculares representam a fase $\alpha$, que se formaram na matrix $\beta$ (Figura 5.4).

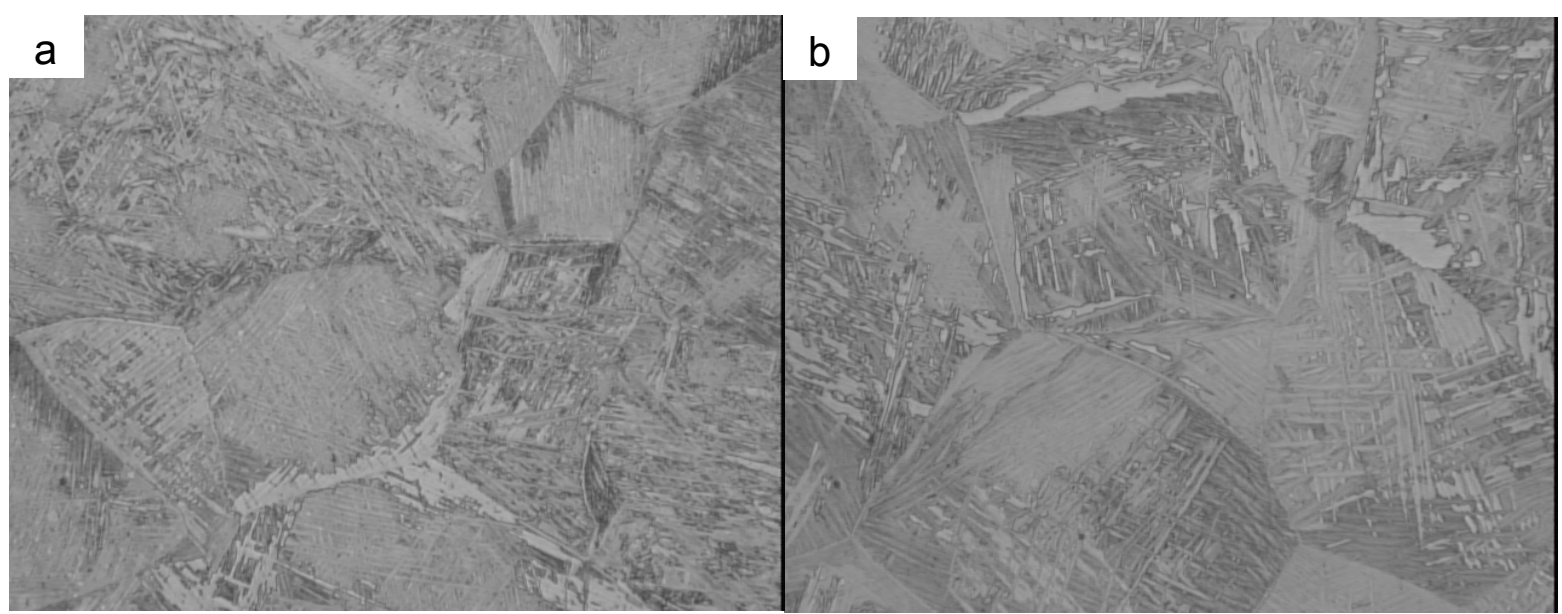

Figura 5.4 - Microestrutura óptica: (a) Liga Ti-6Al-4V fundida em ambiente preenchido com o argônio N-50 (b) Liga Ti-6Al-4V fundida em ambiente preenchido com o argônio Industrial. 
A análise do padrão de fratura da parede externa dos corpos-de-prova oriundos do teste de resistência à tração (Figuras 5.5a e 5.6) evidencia que o Ti CP apresentou alto alongamento antes da fratura, denunciando, portanto, uma fratura do tipo dúctil. Isto pode ser observado pela presença de alguns "cracks" (setas vermelhas) nas figuras 5.5a e 5.6 do $\mathrm{Ti} \mathrm{CP}$.

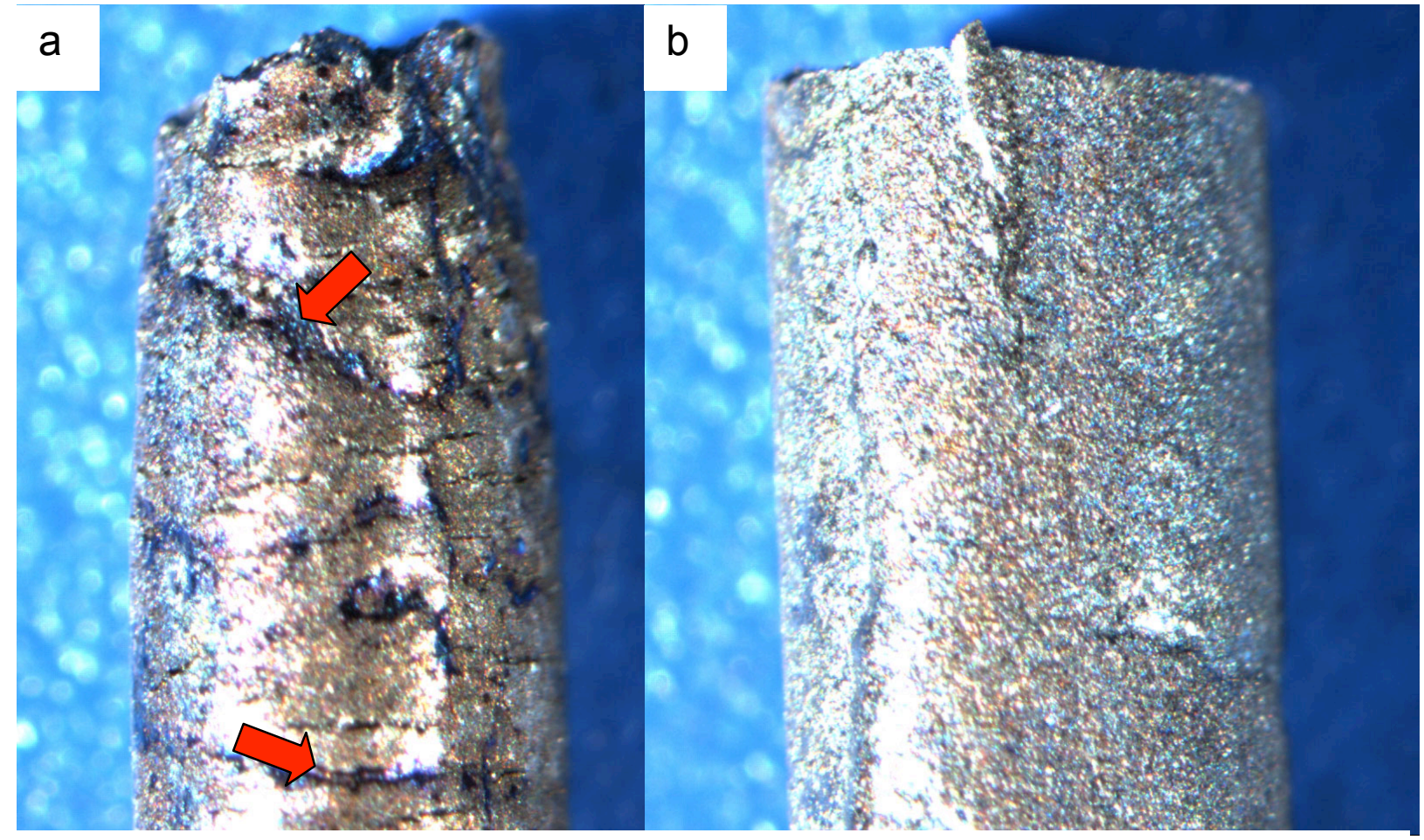

Figura 5.5 - Análise da superfície externa de corpos-de-prova após ensaio de resistência à tração (a) Titânio comercialmente puro, (b) liga Ti-6Al-4V

Outro fator que evidencia a fratura do tipo dúctil é a formação de "dimples" globulares, além da presença de área de escorregamento (Figura 5.7) do Ti CP. 


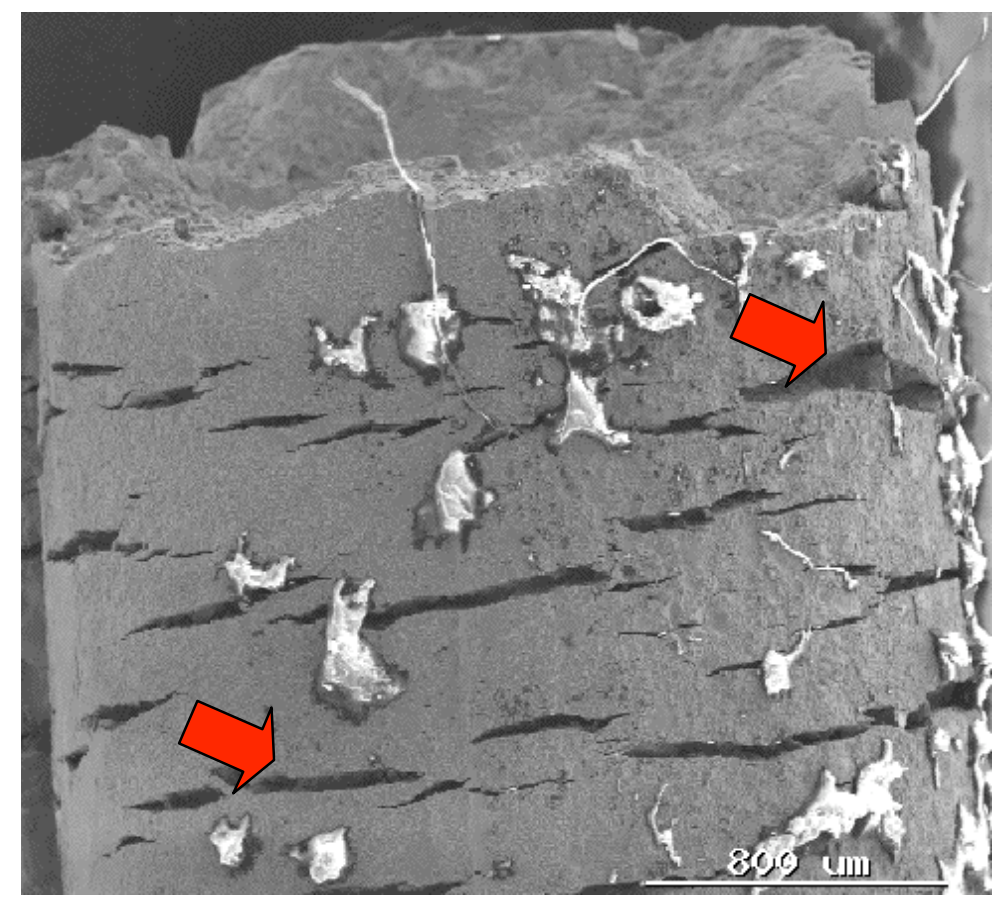

Figura 5.6 - Microscopia eletrônica de varredura: Formação de craks (setas vermelhas) na facє externa do corpo-de-prova de Ti CP

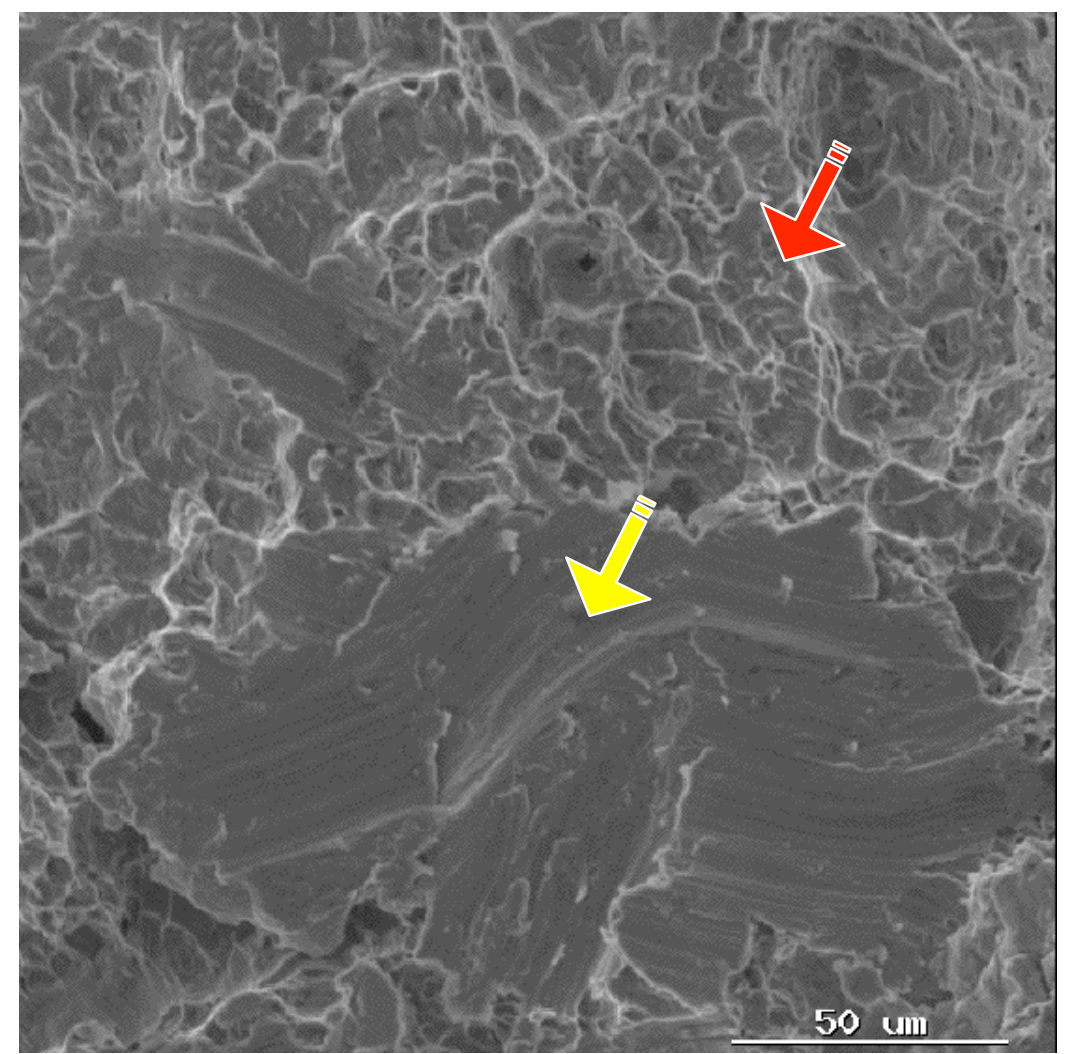

Figura 5.7 - Microscopia eletrônica de varredura: (seta vermelha) formação de "dimples" globulares, (seta amarela) área de escorregamento 
Para a liga Ti-6Al-4V não foram encontradas formações de "craks" o que evidencia fratura ou comportamento do tipo frágil (Figura 5.5b e 5.8).

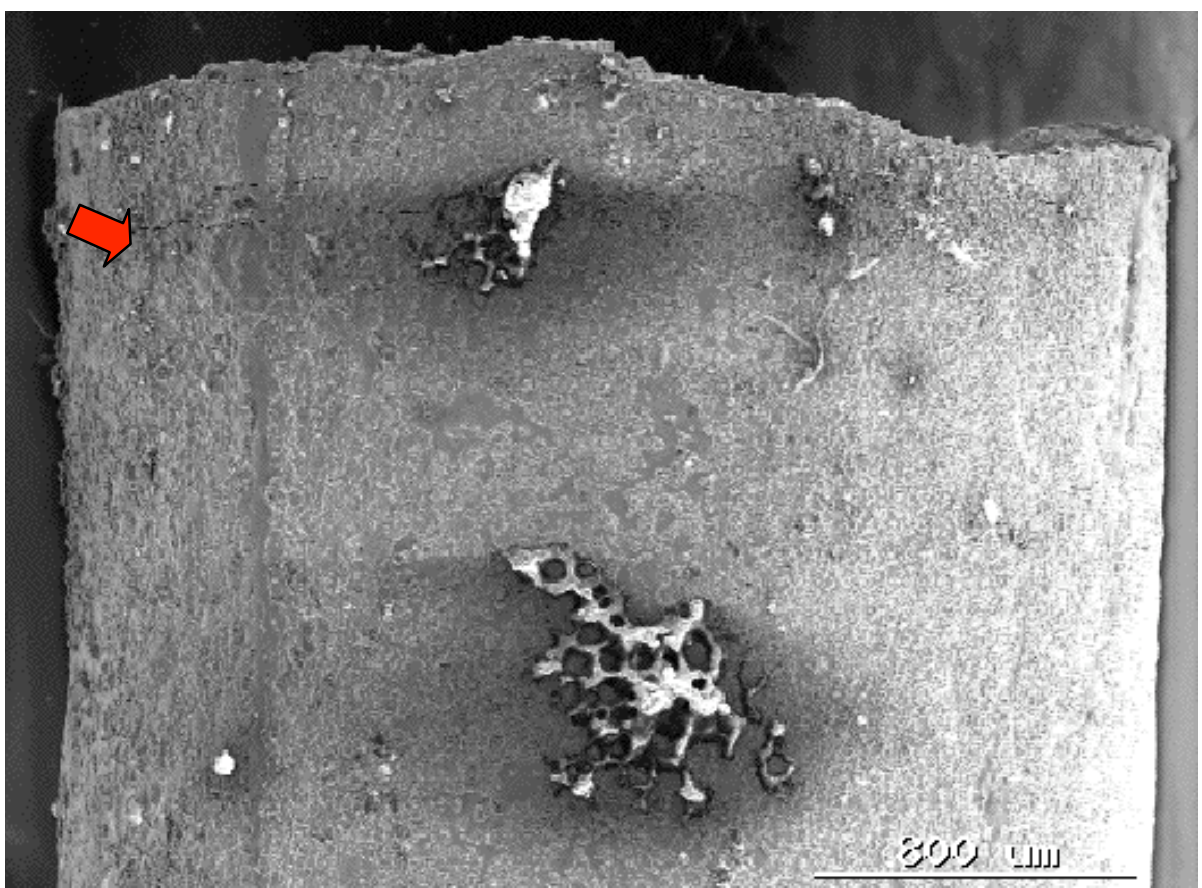

Figura 5.8 - Microscopia eletrônica de varredura da superfície externa da liga Ti-6Al-4V sem a formação de craks

A microscopia eletrônica de varredura também evidenciou o comportamento frágil da liga Ti-6Al-4V (Fig. 5.5b, 5.8 e 5.9) pela presença de clivagem acicular e/ou pequenas cavidades lamelares.

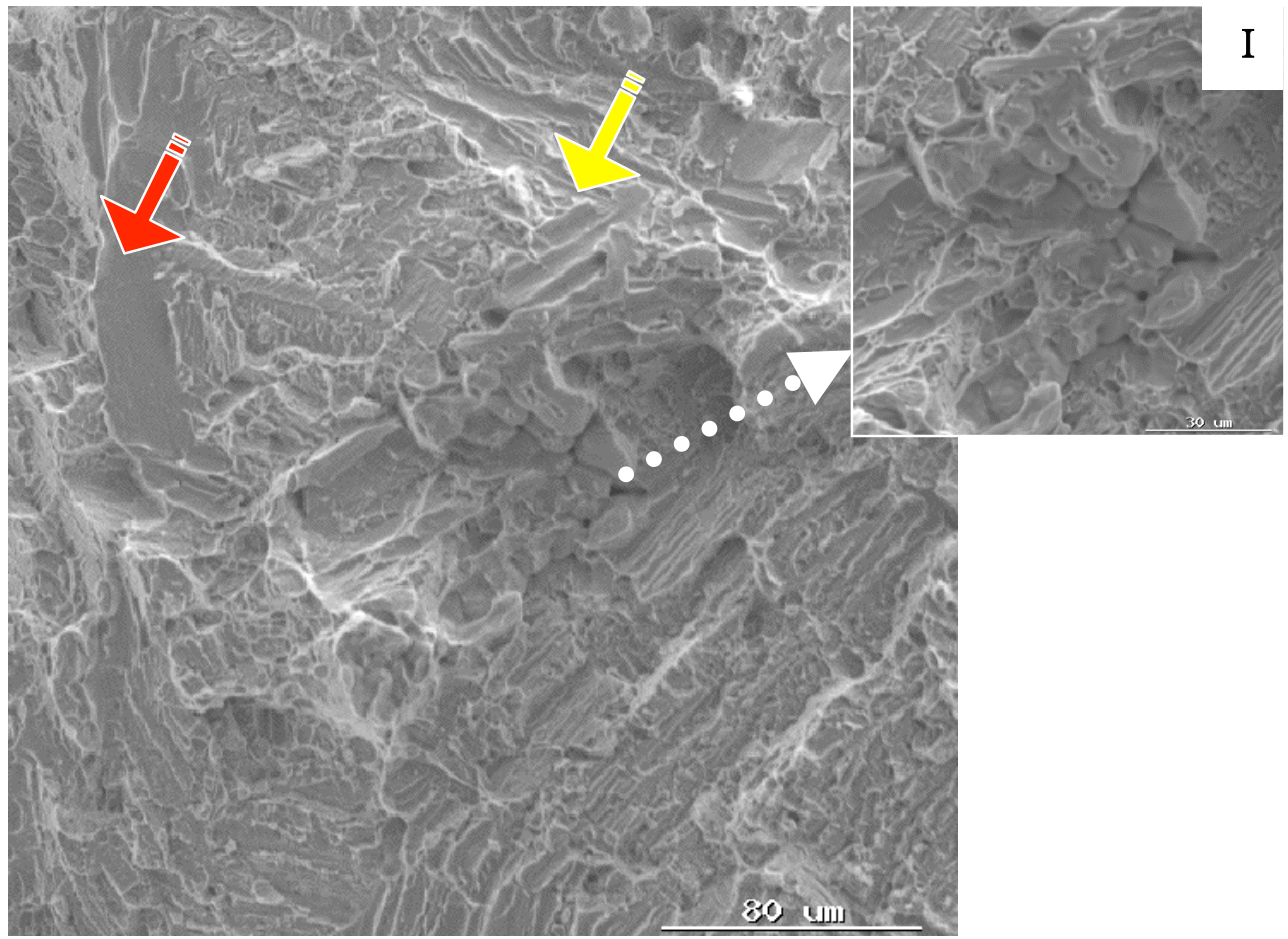

Figura 5.9 - Microscopia eletrônica de varredura da liga Ti-6Al-4V: (seta vermelha) pequena área de estricção, (seta amarela) clivagem lamelar, ( I ) área em destaque, em maior aumento: formação dendrítica 
Com o objetivo de esclarecer os valores numéricos obtidos no teste de microdureza Vickers foi realizada uma leitura de composição através da Espectroscopia de Energia Dispersiva (EDS) na superfície externa do corpo-deprova, além da análise de microscopia ótica.

A Figura 5.10 mostra a microscopia ótica de um espécime de Ti CP fundido com um argônio de alta pureza (99,999\%), fica evidente a formação de diferentes camadas, a mais externa é composta por uma estrutura amorfa, a intermediária é composta por uma leve formação de grãos aciculares e a terceira e mais interna, uma formação de grãos aciculares $(\alpha-\mathrm{Ti})$.

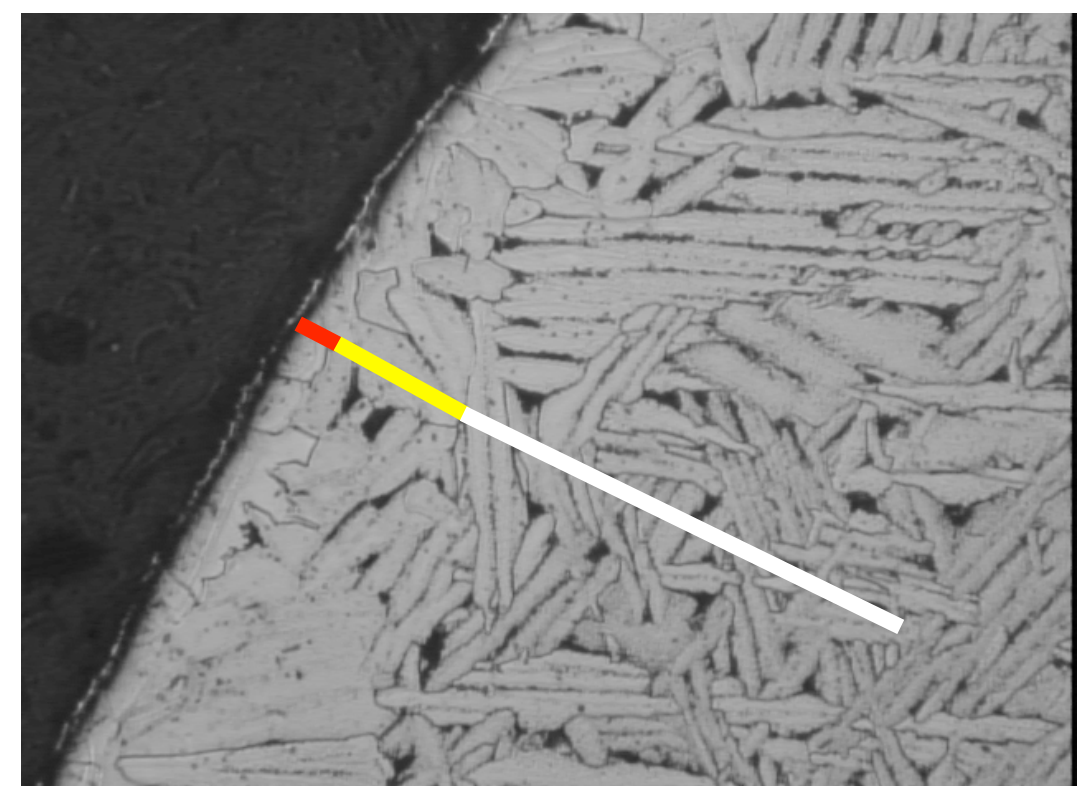

Figura 5.10 - Microscopia ótica do Ti CP espécime fundido com o argônio de alta pureza $\{100 x\}$ : (faixa vermelha) $\alpha$-case, (faixa amarela) estrutura acicular $\alpha$-Ti, (faixa branca) estrutura acicular $\alpha-\mathrm{Ti}$

Para a análise de possíveis contaminantes, foi selecionada uma região da superfície externa do corpo-de-prova do Ti CP, fundido em um ambiente preenchido com um argônio de alta pureza $(99,999 \%)$. Assim, foram realizadas imagens e as análises em determinados pontos. A Figura 5.11 mostra uma mesma área com diferentes tipos de imagem. 


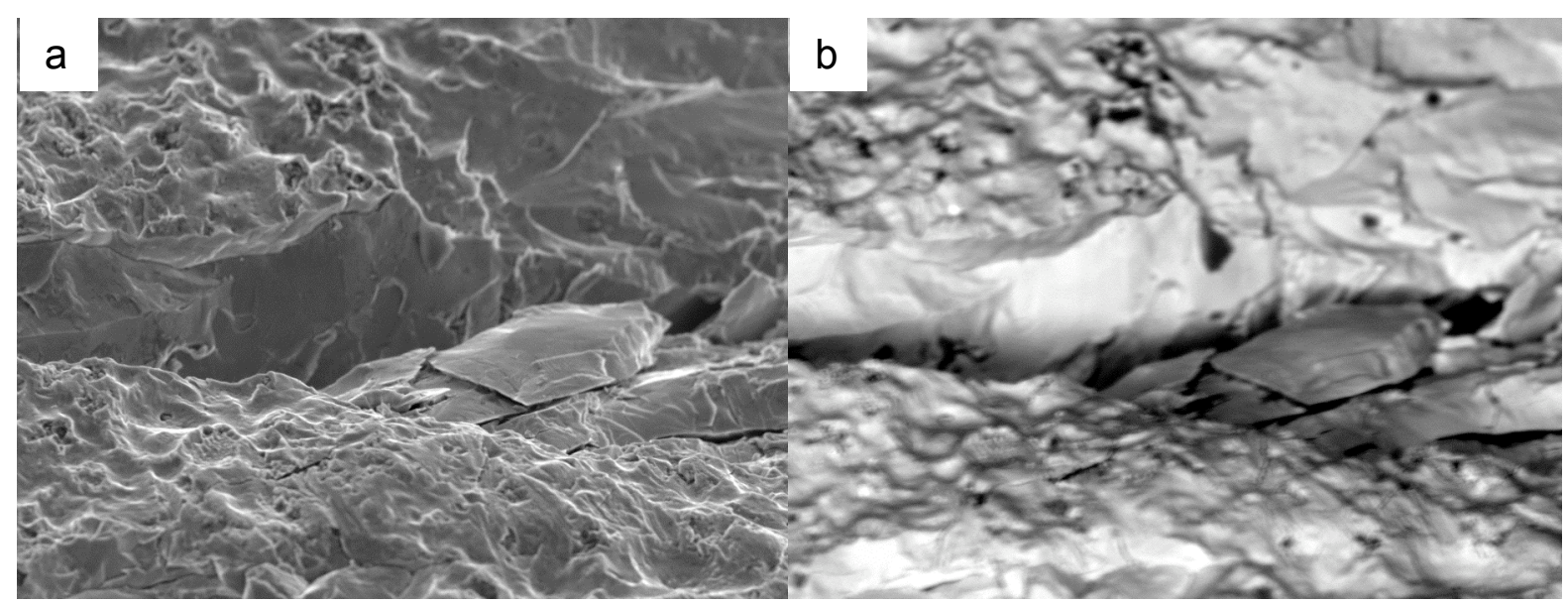

Figura 5.11 - Microscopia eletrônica de varredura da superfície externa de um espécime de Ti CP obtido por: (a) Elétrons secundários e (b) Elétrons retro espalhados

A Figura 5.12 mostra os diferentes pontos, escolhidos em função da visualização de diferentes fases, de leitura da composição realizada na superfície externa do corpo-de-prova.

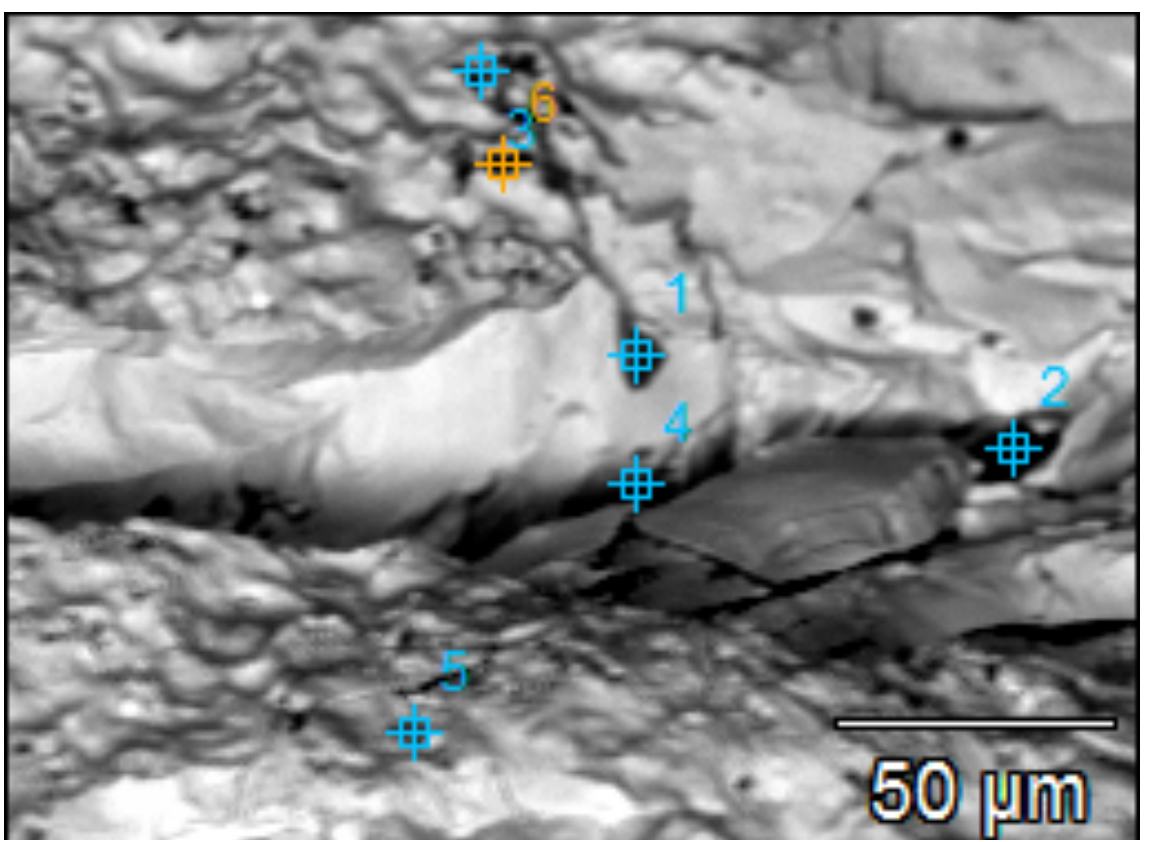

Figura 5.12 - Microscopia eletrônica de varredura da superfície externa de um espécime de Ti CP obtido por elétrons retro espalhados, mostrando diferentes (seis) pontos de leitura de composição

A Figura 5.13 é uma representação gráfica de composição encontrada nos diferentes pontos obtida pelo EDS. O ponto 1 mostra traços do elemento $\mathrm{Si}$, os pontos 2, 4 e 5 mostram praticamente apenas o Ti, já os pontos 3 e 6 indicam a presença de elementos normalmente encontrados em revestimento usados para fundição do titânio e suas ligas como o Al, Mg e Zr. 
Ponto 1

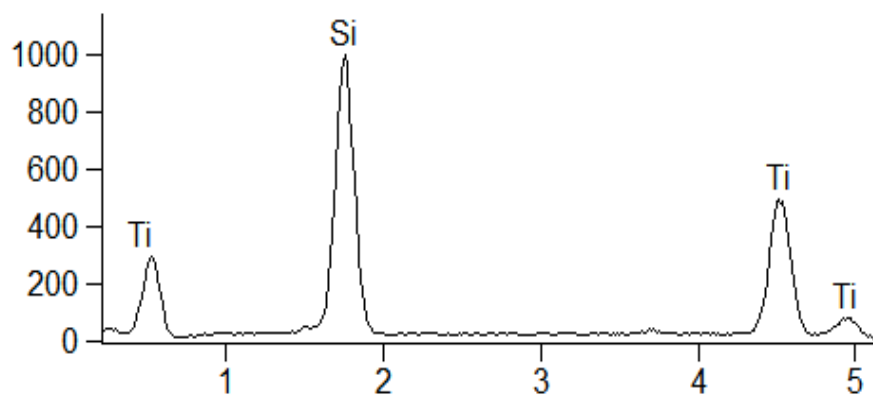

Ponto 3

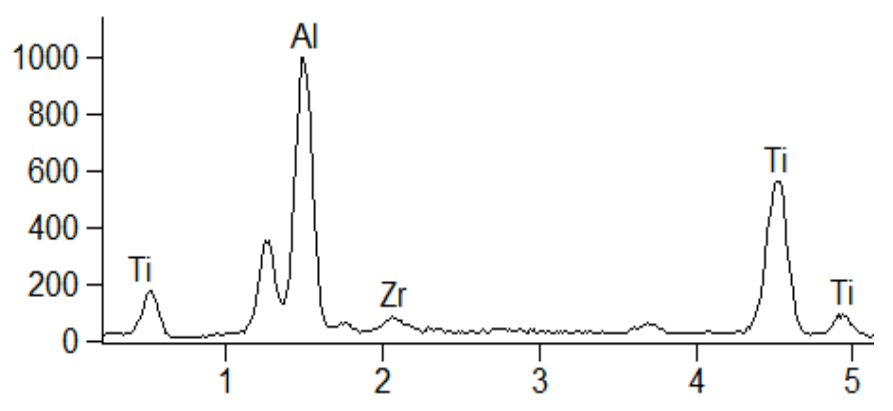

Ponto 5

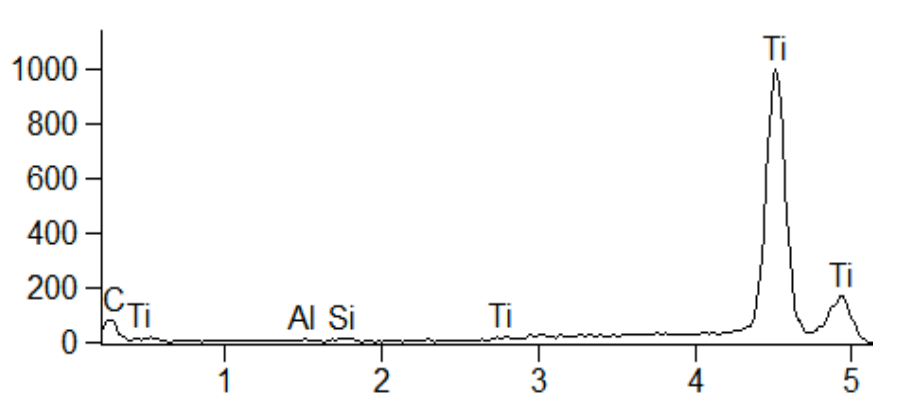

Ponto 2

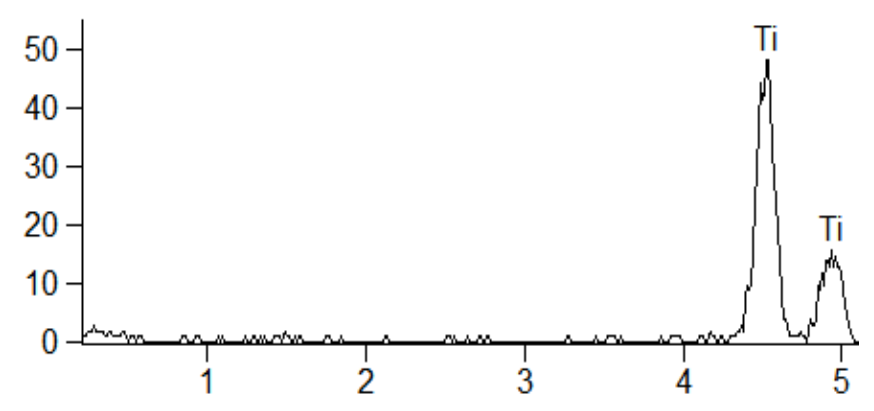

Ponto 4

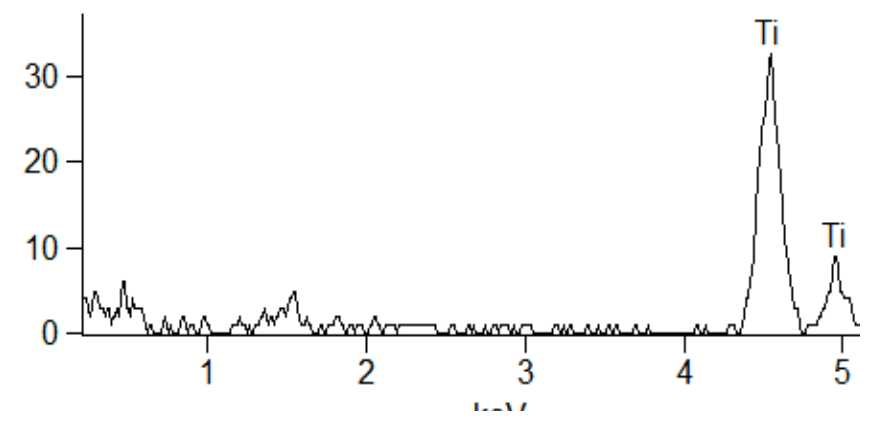

Ponto 6

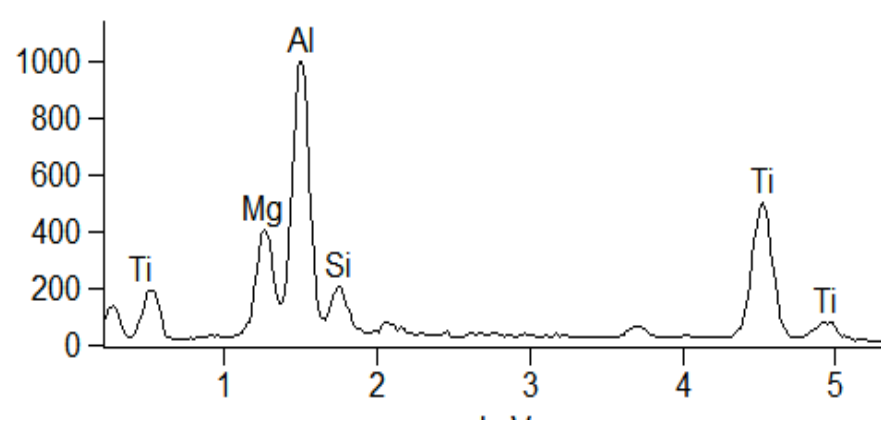

Figura 5.13 - Representação gráfica da análise química realizada por EDS nos diferentes pontos da superfície externa de um espécime de Ti CP fundido em ambiente preenchido pelo argônio $\mathrm{N}-50$ 


\section{DISCUSSÃO}

Vários autores se preocuparam com a pureza do argônio, devido ao fato de que este fator poderia de alguma maneira, alterar as propriedades do titânio (SUNNERKRANTZ; SYVERUD; HER $\varnothing, 1989 ; \mathrm{KIKUCHI}$ et al., 2003; AOKI et al., 2004; SATO et al., 2005; KOIKE et al., 2005). Dentre as diversas alternativas para a redução do custo de fundição, a possibilidade da utilização de um tipo de argônio de baixo custo, como o industrial, certamente seria um importante contribuinte para o uso mais freqüente do titânio.

O risco de realizar uma fundição de titânio em ambiente rico de impurezas, principalmente oxigênio, nitrogênio e hidrogênio, é o de poder provocar uma grande alteração nas propriedades e na composição do material, já que este metal apresenta alta reatividade em temperaturas acima de $600^{\circ} \mathrm{C}$ (VOITIK, 1991). Esta contaminação leva à obtenção de um material frágil, quebradiço e obviamente, de baixo alongamento, devido à formação de composto intermetálicos, soluções substitucionais e intersticiais (MINOSHIMA et al., 2001). Dentre os diversos transtornos causados por esta contaminação está a redução no limite de fadiga e alongamento de grampos e armações em peças de prótese parcial removível (VALLITTU; KOKKONEN, 1995).

No presente estudo, apesar da hipótese que possível contaminação pelas impurezas provenientes do argônio pudesse alterar alguns valores de propriedades mecânicas, ficou claro que isto não ocorreu, já que, estatisticamente não houve diferença entre os tipos de argônio testados. No entanto, foi possível notar alguma sensibilidade quanto à qualidade do argônio, quando da comparação dos valores 
médios de algumas propriedades: limite de proporcionalidade para o Ti CP $(400,6$ e 451,0 MPa, respectivamente para N-50 e o Industrial) e para o Ti-6Al-4V (850,0 e 935,6 MPa, respectivamente para N-50 e o Industrial); resistência à tração para o Ti $\mathrm{CP}(476,4$ e 486,7 MPa, respectivamente para N-50 e o Industrial) e a liga Ti-6Al-4V (898,8 e 975,1 MPa, respectivamente para N-50 e o Industrial); alongamento do Ti CP (18,9 e 16,7\%, respectivamente para N-50 e o Industrial) e para a liga Ti-6Al-4V (2,1 e 1,8\%, respectivamente para N-50 e o Industrial).

Esta tendência pode ser decorrente dos contaminantes encontrados no argônio industrial, principalmente de oxigênio e água presentes em grande quantidade (Tabela 4.2). O titânio é extremamente reativo com quase todos os elementos, particularmente com o oxigênio e o nitrogênio, que podem ser dissolvidos na matriz intersticial, levando a alterações na grade cristalina, que acarreta aumento na dureza e resistência à tração, bem como redução do alongamento (MENAND; HUGUET; NÉRAC-PARTAIX, 1996).

Essa sensibilidade do titânio às impurezas fica mais clara ainda quando se observa os diferentes tipos de titânio comercialmente puro (Ti CP), nota-se que pequenas variações dos elementos $\mathrm{Fe}$ e $\mathrm{O}$ causam grandes mudanças no material, quanto à resistência à tração e alongamento (WANG; FENTON, 1996).

Já as ligas testadas mostraram uma diferença significante, sendo que a liga Ti-6Al-4V apresentou valores maiores de limite de proporcionalidade (892 MPa) e resistência à tração (937 $\mathrm{MPa})$, e valores inferiores de alongamento (1,9 \%).

À temperatura ambiente, o $\mathrm{Ti}$ CP apresenta uma estrutura cristalina hexagonal compacta (hc), neste caso chamada de "fase alfa". Esta estrutura é alterada para uma estrutura cristalina cúbica de corpo centrado (ccc), conhecida 
como "fase beta", sob alta temperatura (acima de $883^{\circ} \mathrm{C}$ ), mas o Ti CP retorna a estrutura hexagonal compacta à temperatura ambiente.

Os maiores valores de resistência à tração, e a diminuição do alongamento do Ti-6Al-4V, se explica pela inclusão do alumínio, um estabilizador da fase alfa e o vanádio, um estabilizador da fase beta, fazendo com que a liga apresente, na temperatura ambiente as fases alfa e beta. Estes elementos, considerados refinadores do grão, podem também contribuir com o aumento da resistência da liga Ti-6Al-4V, fundamentalmente do limite intergranular, sabidamente região de maior resistência à deformação (DONACHIE JR, 1988).

A presença das duas fases (estruturas cristalinas) tem um papel fundamental nas propriedades mecânicas, sendo a responsável pelos altos valores obtidos de limite de proporcionalidade e resistência à tração além do baixo valor alongamento da liga Ti-6Al-4V, quando comparado com o $\mathrm{Ti}$ CP que apresenta apenas uma estrutura cristalina (hexagonal compacta).

Vale a pena mencionar que, as médias de resistência à tração, tanto da Ti CP quanto do Ti-6Al-4V estão de acordo com as encontradas na literatura (AOKI et al., 2004; KIKUCHI et al., 2003; KOIKE et al., 2005; ROCHA et al., 2005). O baixo alongamento obtido pela liga Ti-6Al-4V também é bem próximo aos reportados em outros trabalhos. Já o alongamento do Ti CP verificado neste estudo, apresentou um valor mais elevado do que aqueles relatados por alguns autores (AOKI et al., 2004; KIKUCHI et al., 2005; KOIKE et al., 2005; ROCHA et al., 2005), mas, vai ao encontro dos valores relatados em outros estudos (DONACHIE JR, 1988; HSU et al., 2005).

Para o teste de microdureza, as ligas apresentaram uma diferença considerável, sendo que a Ti-6Al-4V novamente apresentou os maiores valores. 
Entretanto, não foi objetivo do estudo avaliar a diferença entre os materiais, e sim, a influência da qualidade do argônio em função do afastamento da borda externa.

Independente do tipo do titânio utilizado, Ti CP ou as suas ligas, estes materiais apresentam uma alta reatividade com óxidos presente no revestimento. Isto advém da facilidade do titânio em reduzir vários óxidos, assim pode se explicar a alta dureza encontrada nos dois materiais quando testados próximo à margem dos espécime (PAPADOPOULOS; ZINELIS; VARDAVOULIAS, 1999; AOKI et al., 2004).

As camadas formadas na superfície do corpo-de-prova (cp) de titânio, quando fundido em revestimento fosfatado com sílica e alumina, foram descritas por MIYAKAWA et al. (1989): (1) mais externa, rica em silício, fósforo, oxigênio, alumínio e magnésio, resultante da reação do contato direto do metal com o revestimento; (2) esta camada contém oxigênio e alumínio, elementos alfa estabilizadores, daí a origem da denominação, alfa-case; (3) já esta camada exibe concentrações localizadas de silício, fósforo, oxigênio e carbono; (4) em direção à esta quarta camada, o teor de alumínio decresce, se tornando discreta e é constituída de cristais aciculares em arranjo alternado com oxigênio.

Tais camadas são encontradas apenas quando o titânio é fundido com revestimento aglutinado por fosfato (aglutinante) e sílica (cristobalita ou quartzo). Hoje em dia, são utilizados óxidos que apresentam altos valores negativos de energia livre de formação, superiores ou próximos aos do $\mathrm{TiO}_{2}$ como: $\mathrm{Al}_{2} \mathrm{O}_{3}, \mathrm{CaO}$,

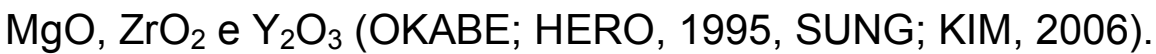

Para Guilin et al. (2007), independentemente do tipo de revestimento utilizado, seja ele a base de $\mathrm{SiO}_{2}, \mathrm{Al}_{2} \mathrm{O}_{3}$ ou $\mathrm{MgO}$, sempre haverá a formação de 3 distintas camadas: (1) camada de óxido, (2) camada de liga e (3) camada de titânio puro, sendo que a primeira e segunda são denominadas camadas de reação. 
Entretanto, cabe ressaltar que, o tamanho desta camada de contaminação está intimamente ligado ao tipo de óxido utilizado para expansão. Como esperado, em função da energia livre de formação, a camada mais contaminada e de maior dureza foi encontrada na superfície dos $\mathrm{cp}$ fundidos com um revestimento a base de $\mathrm{SiO}_{2}$, ao passo que a menor foi encontrada com o MgO. Valores intermediários foram proporcionados com o $\mathrm{Al}_{2} \mathrm{O}_{3}$ (GUILIN et al., 2007).

Devido ao uso de óxidos menos estáveis, ou daqueles que sofrem redução do titânio líquido (os baseados em $\mathrm{SiO}_{2}$ ), a camada de contaminação apresenta normalmente espessura variável e extensa entre 60 e 350 4 m (MIYAKAWA et al., 1989). Mas, vale lembrar que a mensuração dessas camadas de contaminação é bastante sensível à técnica de limpeza, que incluí a usinagem e jateamento dos cp (WATANABE et al., 1997).

Parece claro que a contaminação é extremamente dependente do tipo de revestimento. Aqueles que apresentam óxidos mais estáveis, como Rematitan UltraDentaurum, mostram uma camada de contaminação menor, em torno de 15 a $20 \mu \mathrm{m}$ (ELIOPOULOS; ZENELIS; PAPADOPOULOS, 2005). No presente trabalho não foi mensurada a espessura de contaminação do revestimento nos espécimes, mas ela pode ser inferida em função dos valores de microdureza (Figura 5.2). Assim, para a liga Ti-6Al-4V essa contaminação ficaria em torno de $100 \mu \mathrm{m}$, já para o Ti CP a camada seria mais espessa, por volta de $180 \mu \mathrm{m}$ a partir da superfície externa. Por outro lado, os refratários que conduzem a baixa contaminação do metal, proporcionam uma baixa expansão do molde (HSU et al., 2005).

Uma outra alternativa para a diminuição da camada de " $\alpha$-case", em peças fundidas com revestimento fosfatado/sílica (Ticoat $S+L$, Mafredi), é a diminuição da temperatura do molde, que leva à formação de camada de contaminação com 
apenas $80 \mu \mathrm{m}$ de espessura (ELIOPOULOS; ZENELIS; PAPADOPOULOS, 2005). Entretanto, a diminuição da temperatura do molde, pode comprometer ainda mais o pobre poder de cópia do titânio (OLIVEIRA et al., 2006).

Os altos valores médios de microdureza encontrados próximo à margem, são devidos ao alto teor de oxigênio, um elemento intersticial e $\alpha$-estabilizador. A alta concentração de oxigênio na camada mais externa é viável por causa da grande solubilidade deste elemento em $\alpha-\mathrm{Ti}$, em torno de $31,9 \%$, que juntamente com outros elementos, tais como o $\mathrm{Si}, \mathrm{P}, \mathrm{Al}$ e o Fe levam ao aumento da dureza (PAPADOPOULOS; ZINELIS; VARDAVOULIAS, 1999; DONACHIE JR, 1988).

A presença do Si pode causar a precipitação de compostos intermetálicos, como o $\mathrm{Ti}_{3} \mathrm{Si}$ e o $\mathrm{Ti}_{5} \mathrm{Si}_{3}$, e a contaminação com o alumínio, que além de ser um $\alpha$ estabilizador, também leva a formação de um composto intermetálico, o $\mathrm{Ti}_{3} \mathrm{Al}$. Porém, ambos os elementos, Si e Al, contribuem ainda mais para o aumento da dureza, formando soluções substitucionais na grade cristalina do titânio (PAPADOPOULOS; ZINELIS; VARDAVOULIAS, 1999; SUNG E KIM, 2005).

Entretanto, é consenso entre diversos autores que o oxigênio tem um papel mais marcante no aumento da dureza, por causa da formação de soluções intersticiais na grade do titânio, em função do seu pequeno raio atômico (DONACHIE JR, 1988; TAKAHASHI et al., 1990; WATANABE et al.,1997; ELIOPOULOS; ZENELIS; PAPADOPOULOS, 2005; GUILIN et al., 2007).

Muito embora não exista diferença estatística nos valores mecânicos (limite de proporcionalidade, resistência à tração e microdureza) em relação ao gás utilizado, fica evidente uma tendência a maiores valores quando se utiliza um gás com alto teor de impurezas (Tabela 4.2). Nota-se uma maior quantidade de $\mathrm{O}_{2}$ e de $\mathrm{H}_{2} \mathrm{O}$ no gás Industrial. 
Para Tajima et al. (1994), variações entre 34 e 7 partes por milhão (ppm) de oxigênio no ambiente de fundição, parece não influenciar os valores de microdureza da liga. Entretanto, o uso do vácuo apenas para fazer a limpeza da câmara, pode ocasionar aumento considerável da quantidade de oxigênio presente (120 ppm), o que acarretará aumento substancial da dureza. Entretanto, este aumento se restringe apenas à camada mais externa do metal, sem qualquer alteração no interior da peça.

Vários estudos corroboram um decréscimo nos valores de microdureza à medida que se avança para o interior do cp, mesmo com o uso apenas do argônio de alta pureza (WATANABE et al., 1997; AOKI et al., 2004; ATWOOD; LEE; CURTIS, 2005).

Mas, no presente estudo a alta dureza encontrada nas margens dos $\mathrm{cp}$ ocorreu provavelmente pela contaminação de elementos provenientes do revestimento e não do gás utilizado, como anteriormente descrito (TEODORO et al., 2004).

Além do aumento da microdureza na borda do $\mathrm{cp}$ pôde-se observar, neste estudo, a formação de uma camada com microestrutura amorfa, possível resultado de segregação (Figura 5.10) durante a solidificação (WATANABE et al., 1997; PAPADOPOULOS; ZINELIS; VARDAVOULIAS, 1999; ATWOOD; LEE; CURTIS, 2005).

Do ponto de vista clínico, a camada de contaminação causa uma redução na ductibilidade, do alongamento, da resistência à fadiga, da resistência à corrosão, da biocompatibilidade e na precisão da peça fundida (VALLITU; KOKKONEN, 1995; CAl et al., 1999; CAl et al., 2001; ATWOOD; LEE; CURTIS, 2005). 
Nota-se pelo exposto, que os parâmetros analisados neste trabalho estão absolutamente de acordo com aqueles relatados em diversos outros estudos, fato que, consequentemente, dá crédito à utilização do argônio de baixo custo para fundição de titânio e suas ligas. Entretanto, novos estudos com um argônio industrial se fazem necessários, especialmente aqueles relacionados com a resistência à corrosão. 


\section{CONCLUSÃO}

Podemos concluir que o argônio industrial pode ser uma alternativa para a fundição do titânio comercialmente puro e da liga Ti-6Al-4V, sem nenhum prejuízo das propriedades mecânicas como resistência à tração, limite de proporcionalidade, alongamento e microdureza. 


\section{REFERÊNCIAS ${ }^{1}$}

Ahnlide I, Ahlgren C, Bjorkner B, Bruze M, Lundh T, Moller H, et al. Gold concentration in blood in relation to the number of gold restorations and contact allergy to gold. Acta Odontol Scand 2002;60(5):301-305.

Al-waheidi EM. Allergic reaction to nickel orthodontic wires: a case report. Quintessence Int 1995;26(6):385-7.

Aoki T, Okafor ICI, Watanabe I, Hattori M, Oda Y, Okabe T. Mechanical properties of cast Ti-6Al-4V-XCu alloys. J Oral Reha 2004;31(11):1109-14.

Atwood RC, Lee PD, Curtis RV. Modeling the surface contamination of investment castings. Dent Mater 2005;21(2):178-86.

Bauer JRO, Reis A, Loguercio AD, Rodrigues Filho LE. Resistência à tração e alongamento de ligas de $\mathrm{Ni}-\mathrm{Cr}$ fundidas sob diferentes condições. Rev Pos Grad USP 2006;13(1):83-8.

Bauer JRO, Schroeder M, Loguercio AD, Rodrigues Filho LE, Muench A. Titânio e ligas de titânio: propriedades e técnicas de fundição. Rev Pos Grad USP 2002;9(2):179-85.

Bezzon OL. Allergic sensitivity to several base metals: a clinical report. J. Prosthet Dent 1993;69(3):243-4.

Brendlinger DL, Tarsitano JJ. Generalized dermatitis due to sensitivity to a chrome cobalt removable partial denture. J Am Dent Assoc 1970;81(2):392-394.

Cai Z, Bunce N, Nunn ME, Okabe T. Porcelain adherence to dental cast CP titanium: effects of surface modifications. Biomaterials 2001;22(9):979-86.

Cai Z, Nakajima H, Woldu M, Berglund A, Bergman M, Okabe T. In vitro corrosion resistance of titanium made using different fabrication methods. Biomaterials

\footnotetext{
${ }^{1}$ De acordo com Estilo Vancouver. Abreviatura de periódicos segundo base de dados MEDLINE.
} 
1999;20(2):183-190.

Cai Z, Shafer T, Watanabe I, Nunn ME, Okabe T. Electrochemical characterization of cast titanium alloys. Biomaterials 2003;24(2):213-8.

Cecconi BT, Koeppen RG, Phoenix RD, Cecconi ML. Casting titanium partial denture frameworks: a radiographic evaluation. J Prosthet Dent 2002;87(3):277-80.

Chan DC, Blackman R, Kaiser DA, Chung K. The effect of sprue design on the marginal accuracy of titanium castings. J Oral Rehabil 1998;25(6):424-29.

Collings EW. The physical metallurgy of titanium alloys. Ohio: American Society for Metals; 1984.

Craig RG, Powers JM. Restorative dentals materials. 11ed. St. Loius: Mosby; 2002.

Donachie Jr MJ. Titanium. A Technical Guide. ASM International; Ohio; 1988.

Eliopoulos D, Zinelis S, Papadopoulos T. The effect of investment material type on the contamination zone and mechanical properties of commercially pure titanium castings. J Prosthet Dent 2005;94(6):539-48.

Fenton AH, Jeffrey JD. Allergy to a partial denture casting: case report. Dent J 1978;44(10):466-68.

Guilin Y, Nan L, Yousheng L, Yining W. The effects of differents types of investments on the alpha-case layer of titanium casting. J Prosthet Dent 2007;97(3):157-64.

Fregert S, Kollander M, Poulsen J. Allergic contact stomatitis from gold dentures. Contact Dermatitis 1979;5(1):63-4.

Haberman AL, Pratt M, Storrs FJ. Contact dermatitis from beryllium in dental alloys. Contact Dermatitis 1993;28(3):157-62.

Herø $\mathrm{H}$, Syverud M, Waarli M. Mold filling and porosity in castings of titanium. Dent Mater 1993;9(1):115-8.

Hildebrand HF, Veron C, Martin P. Nickel, chromium, cobalt dental alloys and allergic reactions: an overview. Biomaterials 1989;10(8):545-8. 
Hsu HC, Kikuchi H, Yen SK, Nishiyama M. Evaluation of different bonded investments for dental titanium casting. J Mater Sci Mater Med 2005;16(9):821-5.

Hubler Jr WR, Hubler WR. Dermatitis from a chromium dental plate. Contact Dermatitis 1983;9(5):377-83.

Hung CC, Hou GL, Tsai CC, Huang CC. Pure titanium casting into zirconia-modified magnesia-based investment molds. Dent Mater 2004;20(9):846-51.

Khan MA, Williams RL, Williams DF. The corrosion behaviour of Ti-6Al-4V, Ti-6AI$7 \mathrm{Nb}$ and $\mathrm{Ti}-13 \mathrm{Nb}-13 \mathrm{Zr}$ in protein solutions. Biomaterials 1999;20(7):631-7.

Kikuchi M, Takada Y, Kiyosue S, Yoda M, Woldu M, Cai Z, et al. Mechanical properties and microstructures of Ti-Cu alloys. Dent Mater 2003;19(3):174-81.

Kobayashi E, Wang TJ, Doi H, Yoneyama T, Hamanaka H. Mechanical properties and corrosion resistance of Ti-6Al-7Nb alloy dental castings. J Mater Sci Mater Med 1998;9(10):567-74.

Koike M, Ohkubo C, Sato H, Fujii H, Okabe T. Evaluation of cast Ti-Fe-O-N alloys for dental applications. Mat Sc Eng C 2005;25(3):349-356.

Kononen M, Rintanen J, Waltimo A, Kempainen P. Titanium framework removable partial denture used for patient allergic to other metals: a clinical report and literature review. J Prosthet Dent 1995;73(1):4-7.

Leal MB, Paulino SM, Pagnano VO, Bezzon OL. Influence of investment type and sprue number on the casting accuracy of titanium crown margins. J Prosthet Dent 2006;95(1):42-9.

Lee CM, Ju CP, Chern Lin JH. Structure-property relationship of cast Ti-Nb alloys. J Oral Rehabil 2002;29(4):314-22.

Lin CW, Ju CP, Chern Lin JH. A comparison of the fatigue behavior of cast Ti-7.5Mo with c.p. titanium, Ti-6Al-4V and Ti-13Nb-13Zr alloys. Biomaterials 2005;26(16):2899907.

Melocini MA. Ajuste cervical de fundições de titânio, tipo coroa, em função de revestimentos e técnicas. 82p. [Tese de Doutorado]: São Paulo -Faculdade de Odontologia da USP; 2000. 
Menand A, Huguet A, Nérac-Partaix A. Interstitial solubility in [gamma] and [alpha]2 phases of TiAl-based alloys. Acta Mater 1996;44(12):4729-37.

Minoshima K, Obara K, Minamino N, Komai K. Environmental fatigue crack growth in titanium aluminides and hydrogen evolution behaviour. Fatigue Fract Eng Mater Struct $2001 ; 24(12): 803-16$.

Miyakawa O, Watanabe K, Okawa S, Nakano S, Kobayashi M, Shiokawa N. Layered structure of cast titanium surface. Dent Mater J 1989;8(2):175-85.

Moller H. Dental gold alloys and contact allergy. Contact Dermatitis 2002;47(2):63-6.

Niinomi M. Mechanical properties of biomedical titanium alloys. Mat Sc Eng A 1998;243(1):231-6.

Oliveira PC, Adabo GL, Ribeiro RF, Rocha SS. The effect of mold temperature on castability of CP Ti and Ti-6Al-4V casting into phosphate bonded investment materials. Dent Mater 2006;22(12):1098-102.

Okabe T, Herø H. The Use of Titanium in Dentistry. Cells and Materials 1995;5(2):211-30.

Okazaki Y, Gotoh E. Comparison of metal release from various metallic biomaterials in vitro. Biomaterials 2005;26(1):11-21.

Papadopoulos T, Zinelis S, Vardavoulias M. A metallurgical study of the contamination zone at the surface of dental Ti castings, due to the phosphatebonded investment material: the protection efficacy of a ceramic coating, J Mat Sci 1999;34(15):3639-46.

Parr GR, Gardner LK, Toth RW. Titanium: the mystery metal of implant dentistry. Dental materials aspects. J Prosthet Dent 1985;54(3):410-14.

Päßler K, Mann E. Der dentale Titangubß - Grundlagen, Technologie und werkstoffundliiche Bewertung. Quintessenz Zahntech 1991;17(6):717-26.

Rocha SS, Adabo GL, Vaz LG Henriques GE. Effect of thermal treatments on tensile strength of commercially cast pure titanium and Ti-6Al-4V alloys. J Mater Sci Mater Med 2005;16(8):759-66. 
Sato H, Kikuchi M, Komatsu M, Okuno O, Okabe T. Mechanical Properties of Cast Ti-Hf Alloys. J Biomed Mater Res Part B: Appl Biomater 2005 72(2):362-7.

Semlitsch MF, Weber H, Streicher RM, Schon R. Joint replacement components made of hot-forged and surface-treated Ti-6Al-7Nb alloy. Biomaterials. 1992;13(11):781-8.

Shepard FE, Moon PC, Grant GC, Fretwell LD. Allergic contact stomatitis from a gold alloy--fixed partial denture. J Am Dent Assoc 1983;106(2):198-9.

Shukla AK, Balasubramaniam R, Bhargava S. Properties of passive film formed on CP titanium, Ti-6Al-4V and Ti-13.4Al-29Nb alloys in simulated human body conditions. Intermetallics 2005:13(6):631-7.

Sung SY, Kim YJ. Alpha-case formation mechanism on titanium investment castings. Mater Sci Eng A 2005;405(1):173-7.

Sunnerkrantz PA, Syverud M, Herø H. Effect of casting atmosphere on the quality of Ti-crowns. Scand J Dent Res 1989;98:268-72.

Syverud, M., Okabe, T., Herø, H. Casting of Ti-6Al-4V alloy compared with pure Ti in an Ar-arc casting machine. Eur J Oral Sci 1995 103(5):327-330.

Taira M, Moser JB, Greener EH. Studies of Ti alloys for dental castings. Dent Mater 1989;5(1):45-50.

Tajima K, Matsuda S, Yokoyama Y, Kakigawa H, Kozono Y. Efficacy of gas purging for titanium casting. Dent Mater J 1994;13(2):206-13.

Takahashi J, Kimura H, Lautenschlager EP, Chern Lin JH, Moser JB, Greener EH. Casting pure titanium into commercial phosphate-bonded $\mathrm{SiO} 2$ investment molds. J Dent Res 1990;69(12):1800-5.

Teodoro OMND, Barbosa J, Duarte Naia M, Moutinho AMC. Effect of low level contamination on TiAl alloys studied by SIMS. Appl Surf Sci 2004;231-232(15):854858.

Thomas CJ, Lechner S, Mori T. Titanium for removable dentures. II. Two-year clinical observations. J Oral Rehabil 1997;24(6):414-8. 
Tsuruta K, Matsunaga K, Suzuki K, Suzuki R, Akita H, Washimi Y, et al. Female predominance of gold allergy. Contact Dermatitis 2001;44(1):55-56.

Vallittu PK, Kokkonen M. Deflection fatigue of cobalt-chromium, titanium, and gold alloy cast denture clasp. J Prosthet Dent 1995;74(4):412-9.

Voitik AJ. Titanium dental castings, cold worked titanium restorations-yes or no? Trends Tech Contemp Dent Lab 1991;8(10):23-34.

Waldemarin RF, Crosara S, Zaniquelli O, Bezzon OL. Efeito da diluição do Rematitan Plus líquido sobre as dimensões de uma incrustação MOD. Pesqui Odontol Bras 2000;14(3):283-6.

Wang RR, Fenton A. Titanium for prosthodontic applications: a review of the literature. Quintessence Int 1996;27(6):401-8.

Wataha JC. Alloys for prosthodontic restorations. J Prosthet Dent 2002;87(4):351-63.

Wataha, J. C. Biocompatibility of dental casting alloys: a review. J Prosthet Dent 2000;83(2):223-34.

Watanabe I, Watkins JH, Nakajima H, Atsuta M, Okabe T. Effect of pressure difference on the quality of titanium casting. J Dent Res 1997;76(3):773-9.

Zinelis S. Effect of pressure of helium, argon, krypton, and xenon on the porosity, microstructure, and mechanical properties of commercially pure titanium castings. $J$ Prosthet Dent 2000;84(5):675-82. 